Review

\title{
Deep Eutectic Solvents (DESs) as Green Extraction Media of Beneficial Bioactive Phytochemicals
}

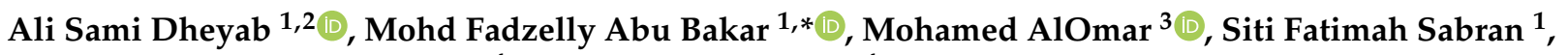 \\ Ahmad Fathi Muhamad Hanafi ${ }^{4}$ and Azman Mohamad ${ }^{4}$ \\ 1 Faculty of Applied Sciences and Technology, Universiti Tun Hussein Onn Malaysia (UTHM)—Pagoh Campus, \\ Muar 84600, Johor, Malaysia; gw180014@siswa.uthm.edu.my (A.S.D.); fatimahsb@uthm.edu.my (S.F.S.) \\ 2 Department of Medical Laboratory Techniques, Al Maarif University College, Ramadi 31001, Iraq \\ 3 Department of Civil Engineering, Al Maarif University College, Ramadi 31001, Iraq; \\ mohd.alomar@yahoo.com \\ 4 UWG Marketing \& Distributors Sdn. Bhd., Lot 7068, PT 5117, Kedai Tingkat Atas Taman D’Wanza, Kg Gong \\ Kepas Dalam, Kampung Raja, Kuala Terengganu 22200, Terengganu, Malaysia; \\ ahmadfathihanafi@gmail.com (A.F.M.H.); unlimitedwealthglobal@gmail.com (A.M.) \\ * Correspondence: fadzelly@uthm.edu.my
}

check for updates

Citation: Dheyab, A.S.; Abu Bakar, M.F.; AlOmar, M.; Sabran, S.F.;

Muhamad Hanafi, A.F.; Mohamad, A. Deep Eutectic Solvents (DESs) as

Green Extraction Media of Beneficial Bioactive Phytochemicals. Separations 2021, 8, 176. https://doi.org/ 10.3390 /separations 8100176

Academic Editors: Angela Sorbo, Claudia Zoani and Daniele Passeri

Received: 12 July 2021

Accepted: 9 September 2021

Published: 7 October 2021

Publisher's Note: MDPI stays neutral with regard to jurisdictional claims in published maps and institutional affiliations.

Copyright: (c) 2021 by the authors. Licensee MDPI, Basel, Switzerland. This article is an open access article distributed under the terms and conditions of the Creative Commons Attribution (CC BY) license (https:// creativecommons.org/licenses/by/ $4.0 /)$.

\begin{abstract}
Deep eutectic solvents (DES) are a mixture of two or more components and are classified as ionic solvents with special properties such as low volatility, high solubility, low melting points, low-cost materials and are less toxic to humans. Using DES has been suggested as an eco-friendly, green method for extraction of bioactive compounds from medicinal plants and are a safe alternative for nutritional, pharmaceutical and various sector applications. Conventional solvent extraction methods present drawbacks such as long extraction period, safety issues, harmful to the environment, costly and large volume of solvents required. The extraction method with DES leads to higher extraction yield and better bioactivity results as compared to the conventional solvents. This review provides a summary of research progress regarding the advantages of using DES to extract bioactive compounds such as phenolic acid, flavonoids, isoflavones, catechins, polysaccharides, curcuminoids, proanthocyanidin, phycocyanin, gingerols, ginsenosides, anthocyanin, xanthone, volatile monoterpenes, tannins, lignin, pectin, rutin, tert-butyl hydroquinone, chlorogenic acids, resveratrol and others, as opposed to using conventional solvents. The bioactivity of the extracts is determined using antioxidant, antibacterial and antitumor activities. Hence, DESs are considered potential green media with selective and efficient properties for extracting bioactive ingredients from medicinal plants.
\end{abstract}

Keywords: medicinal plants; deep eutectic solvents; green extraction; phytochemical; bioactivity

\section{Introduction}

Bioactive compounds of medicinal plants, such as phenolics, alkaloids, flavonoids, terpenoids, polysaccharides, lipids and peptides have several benefits, such as antioxidant, antibacterial and anti-inflammatory properties as well as protective effects against diseases [1,2]. These bioactive compounds are widely used in agrochemical, pharmaceutical and cosmetic industries [3] as well as in replacing synthetic material additives and improving quality of food products [4-6]. Natural bioactive compounds have been extracted from various living organisms, such as plants, fruits and algae. Different bioactive components require different extraction techniques [7]. The activity of these compounds also varies depending on many points under investigation; a study of the physiological effect of bioactive compounds on humans is thus required in the long term [1].

Extraction techniques are classified into two major types: conventional techniques include percolation, maceration, Soxhlet extraction and non-conventional techniques such as microwave-assisted extraction, ultrasound-assisted extraction and enzyme-assisted extraction $[8,9]$. The most bioactive compounds are extracted from plants by various 
processes, mostly using different aqueous-organic solvents, such as hexane, methanol, benzene, chloroform, petroleum ether and acetone [10]. In general, non-conventional techniques have higher efficiency than conventional techniques because they require shorter extraction time, lower cost and significant purity of the compounds. Both techniques present several limitations, such as toxicity of traditional solvents (such as methanol and hexane), thermal instability, low bioactive compound recovery from traditional solvents and possible effects on the compound's chemical structures due to various pathways [11].

Water is the most commonly used medium in pharmaceutical, agrarian and nourishment businesses because its physical and chemical characteristics satisfy most of the compulsory conditions required by the U.S. Food and Drug Administration (FDA). However, water is only effective against polar compounds and has less effect on non-polar compounds [12]. In this regard, an appropriate extraction solvent that exerts less unfavorable impacts on the environment should be developed to replace ordinary chemical strategies. Utilization of green solvents to supplant certain conventional and dangerous solvents is wanted in industries [13].

Green solvents should have significant attributes, such as non-flammability, thermal stability, chemical soundness, low volatility and low toxicity and due to high environmental concerns, green solvents have received high scientific attention as a possible replacement for conventional organic solvents $[14,15]$. For instance, the use of deep eutectic solvent (DES) and ionic liquid (IL) in bioactive compound extraction is a green and successful technique [16,17]. However, ILs exert harmful effects on health and the environment and have high cost [18]. In this regard, scholars have focused on applications of DES because of their exceptional physicochemical properties, such as lower toxicity, higher biodegradability and lower cost than ILs [19-21]. In addition, researchers prefer the benefits of alternative solvents over conventional organic solvents to obtain the ultimate extract at specific and identical times. As such, alternative solvents that are not only ecological but also produce good quality and safe extracts have been developed [22]. Based on the combination of essential metabolites, recently developed DESs comprise sugar alcohols, sugars, amino acids and natural acids. This unused concept of DES has alluded to a "natural deep eutectic solvent" [23]. Many reports have revealed the selectivity of DES in extracting bioactive compounds, such as flavonoids, polyphenols, phenolic acids, saponins and anthraquinones, from different natural sources [4,24].

All the previous reviews included the usefulness of deep eutectic solvents in extracting bioactive compounds from medicinal plants and focused on the recovery amounts of bioactive compounds compared to conventional solvents [25-28]. However, this review aims to summarize the latest efforts dedicated to application of DES in extraction of bioactive compounds and examination of their biological activities, including antioxidant, antibacterial properties and anti-tumor activity.

\section{Methodology}

The review methodology was performed on published research in journals (Figure 1). The search process in relevant literature included articles from Science Direct and Scopus electronic databases by using "deep eutectic solvents" AND "plants extraction" as general keywords. The resulting articles were screened using accurate specific terms including "bioactivity," "bioavailability," "antioxidant," "antibacterial" and "In-vitro studies." The total articles obtained based on the keywords were $n=185$. The search focused on specific terms used in obtained articles based on data validation. Consequently, 41 articles were used in this review. 


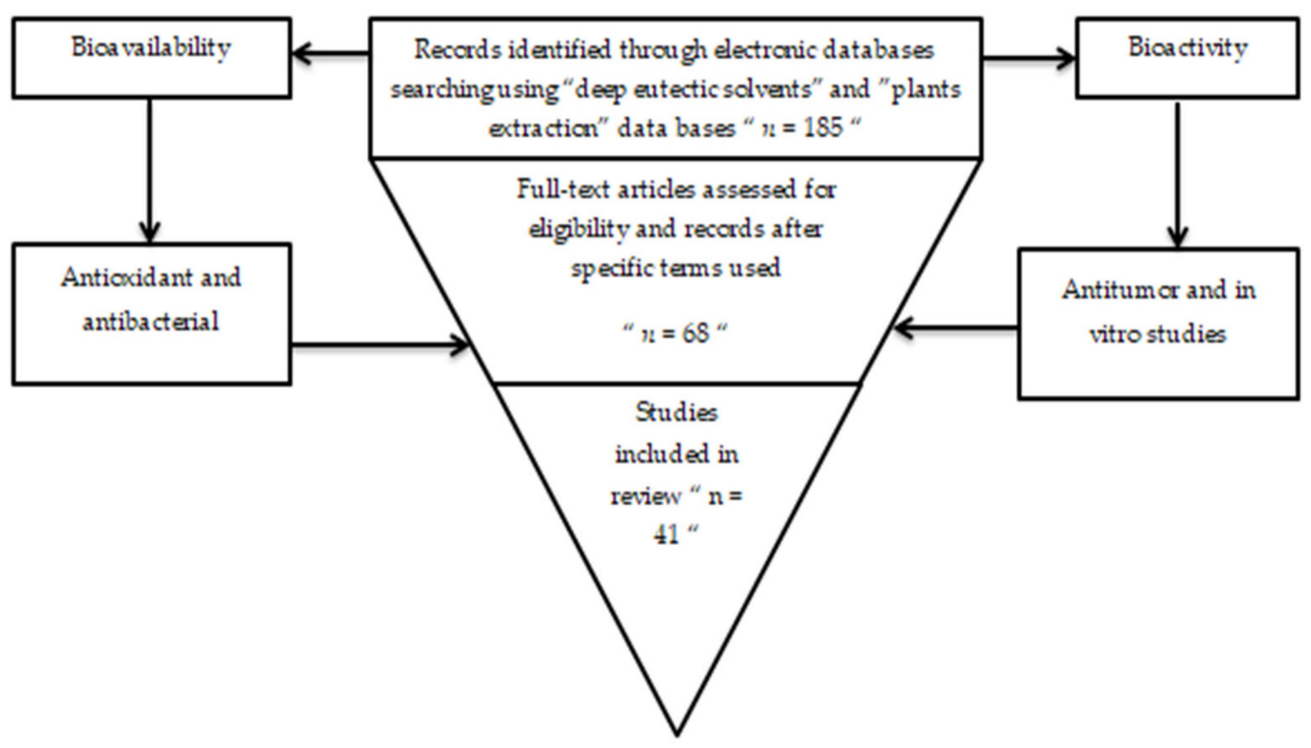

Figure 1. This is a figure for steps of the search process.

\section{Deep Eutectic Solvents (DES): A Brief Overview}

In 2003, Abbot et al. synthesized the first DES from a mixture of choline chloride $(\mathrm{ChCl})$ and urea. In subsequent years, other DESs were discovered, including those synthesized by mixing choline chloride with various carboxylic acids (oxalic, malonic and succinic acids) [29]. The efficiency of DES for extraction of bioactive materials from plants was also investigated [30]. DES or NDES are easily prepared by mixing two or more components, such as choline chloride, maleic acid, citric acid, acetic acid, malic acid, fructose, sucrose, glucose, trehalose and water [31]. The mixture is mixed and stirred at a specific temperature until a clear homogeneous and viscous liquid is obtained [32]. The liquid is cooled to room temperature and is not subjected to any purification step. In general, DES is synthesized using different process times [33]. Choline chloride is the most widely used salt because it is inexpensive, used as a supporting nutrient in the poultry field and biodegradable [34]. Considering the various structural components of DES, scholars have studied their physicochemical properties, such as melting point, density, polarity, conductivity and viscosity. The melting points of the DES mixtures are lower than those of individual compounds [34]. The melting point is not fixed in all DES types but dependent on DES components, such as hydrogen bond donor (HBD), hydrogen bond accepter (HBA) and molar ratio. When choline chloride and urea are mixed in different molar ratios of $1: 1$ and $1: 2$, the freezing points of DES mixtures are $>50{ }^{\circ} \mathrm{C}$ and $12{ }^{\circ} \mathrm{C}$, respectively [35]. The melting point of DES is determined by the HBD ratio because the increased interaction between the salt anionic groups with the hydrogen bond will lead to decreased interactions with the salt cationic groups [36]. The DES density is an important physical property that has an estimated higher value than the water density value [37]. The notable variations in the DES mixtures in terms of density are due to their different individual molecular compositions, and their density is higher than that of their individual starting materials. This is most probably dependent on the concept of hole theory [36]. For instance, urea and acetamide have densities of 1.32 and $1.16 \mathrm{~g} \mathrm{~cm}^{-3}$, respectively, while the DES of $\mathrm{ZnCl2}$-acetamide (1:4) and $\mathrm{ZnCl} 2$-urea (1:3.5) have densities of 1.36 and $1.63 \mathrm{~g} \mathrm{~cm}^{-3}$, respectively [35]. The densities of DES mixtures also have major effects on the molar ratios of their individual components [38].

The polarity of the compositions of DES mixtures is also a particularly important characteristic of the modulation mixture in extraction. Variations in DES polarity depend on individual compositions and are believed to be related to the molecular structure of HBD $[13,39]$. Moreover, the temperatures of DES are important given that increasing temperature leads to a decrease in the polarity of DES. In addition, increases in temperature 
reduce the hydrogen-bond donating acidity of DES [40]. Most DES mixtures have viscosity greater than $100 \mathrm{cP}$ at room temperature, which is higher than those of other solvents and traditional small molecule solvents [34-36]. The highly viscous nature is probably due to the presence of a huge network in the hydrogen bond of the compounds, resulting in decrease in the mobility of free species inside DES. Moreover, electrostatic interactions may contribute to the high viscosity of DES [35]. Although high viscosity can be very beneficial when processing single drop micro-extraction, it may negatively affect other extraction procedures. However, this defect is usually avoided by increasing the temperature during extraction or by adding water $[3,41]$. Conductivity is another physical property of DES. These solvents have poor conductivity, lower than $2 \mathrm{mS} \mathrm{cm}^{-1}$ at room temperature, due to their high viscosity [35]. Thus, elevated temperature will lead to a significant increase in DES conductivity due to the decline in viscosity [13,42]. A previous study reported that modification in the molar ratios of DES components affects the conductivity property; that is, increasing the amount of $\mathrm{ChCl}$ to glycerol will increase the conductivity (from $0.74 \mathrm{mS} \mathrm{cm}^{-1}$ for a molar ratio of $1: 4 \mathrm{ChCl} /$ glycerol to $1.30 \mathrm{mS} \mathrm{cm}^{-1}$ for a molar ratio of 1:2 ChCl/glycerol) [29,42]. Table 1 summaries the advantages and disadvantages of DESs from general perspective

Table 1. Main advantages and disadvantages of DESs.

\begin{tabular}{|c|c|c|c|}
\hline Conditions & Advantages & Disadvantages & Ref \\
\hline Synthesis & Simple preparation & Nil & [43] \\
\hline Economy & Very low price and available & Nil & \\
\hline $\begin{array}{l}\text { Physiochemical } \\
\text { properties }\end{array}$ & $\begin{array}{l}\text { High reactivity, non-sensitive to water, } \\
\text { non-flammability and thermal stability }\end{array}$ & High viscosity & [44] \\
\hline Environmentally & $\begin{array}{l}\text { Biodegradable, biocompatible, } \\
\text { renewable and low toxicity }\end{array}$ & $\begin{array}{l}\text { Some types have } \\
\text { toxicity }\end{array}$ & [45] \\
\hline
\end{tabular}

\section{Advance Plant Extraction Techniques by DES}

The disadvantages of conventional plant extraction techniques are seen in the Soxhlet technique, whereby excessive volumes of solvent are used and time is wasted in plant extraction, resulting in lower volume yield. Advanced extraction techniques are known for their short extraction time, reduced volume of organic and hazardous solvents and simple operation, high extraction yield and low energy consumption; as such these techniques are categorized as "Green Extraction."

Ultrasound-assisted extraction (UAE) is used for extraction and analysis of different types of bioactive compounds and crude extract from a variety of plant materials [46]. This technique uses energy with low frequency $(>20 \mathrm{kHz})$ and high power $(80-200 \mathrm{~W})$ and an ultrasonic bath or probe. The extraction principle depends on the cavitation phenomenon, which creates bubbles by disrupting and collapsing cell walls to release the target compounds and allow diffusion of solvents by working the UAE matrix; this technique is efficient and is time saving [47]. DES based on ultrasound-assisted extraction has been reported as a greener approach for bioactive compounds extraction than using conventional organic solvents [48]. Several types of DESs have been used in UAE to extract bioactive compounds from ginger. The extraction condition included 1:4 L-carnitine:1,3-butanediol at $40{ }^{\circ} \mathrm{C}$ for $30 \mathrm{~min}$, resulting in higher yield of gingerols extracted than those of ethanol and water extraction; furthermore, UAE ginger extracts showed higher antioxidant capability [49].

Another advanced extraction method for bioactive compounds from biological matter is microwave-assisted extraction (MAE), which uses two types of equipment [50]. The principle of MAE depends on the use of electromagnetic radiation waves (typically $2.45 \mathrm{GHz}$ ) by direct interaction with the sample through heating and continuous dipole rotation. This process leads to the degradation of plant cell tissues and induces ion flow to release active compounds from the intracellular and cell membrane; MAE has high extraction efficiency [51]. The efficiency of this method depends on the nature of the sample and 
solvent. Therefore, this type of extraction has low cost and saves solvent volume compared with traditional extraction techniques. Furthermore, industrial scale-up approaches of MAE have been developed due to its operational simplicity [52,53]. Five main flavonoids from sea buckthorn leaves were extracted by MAE using 12 kinds of DES (choline chloride as HBA) and $70 \%$ ethanol. Under the optimal condition of $64{ }^{\circ} \mathrm{C}$ for $17 \mathrm{~min}$, this technique provides an improved performance, which is significantly superior to DES-HRE and DESUAE and leads to a high extraction yield of $20.82 \mathrm{mg} / \mathrm{g}$ for target flavonoids within a short time. The extracted has also shown better antioxidant activity, while being low energy and eco-friendly [54].

In recent years, pressurized liquid extraction (PLE) has been commonly used [55]. This automated method uses a suitable solvent for bioactive compound recovery similar to how water depends on an increased temperature with high pressure to induce solvent diffusivity and enhance plant extraction. The process decreases pollution and converts waste into resources [56]. In 2009, a new kind of PLE was introduced with a cavitation method called negative-pressure cavitation extraction (NPCE) and another green technique known as subcritical water extraction (SWE) or pressurized hot water extraction (PHWE), which uses water under a critical boiling point [55]. Recently, green extraction was proposed to obtain flavonoids from Equisetum palustre L. by using nine types of DES-based negative pressure cavitation method (NPC and DES). The results showed higher extraction yield compared with methods using conventional ethanol solvents. Higher yields were observed when separating four main isoflavonoids from Dalbergia odorifera T. Chen leaves through negative-pressure cavitation-assisted extraction with 11 different types of green and efficient DESs [57,58]. Phenolic compounds were extracted from mangosteen pericarps by batch and semi-batch systems of subcritical water extraction, where the addition of DES at $10-30 \%$ volume results in high extraction yield and antioxidant activity [59].

Enzyme-assisted extraction (EAE) is another advanced green technique because it usually uses aqueous media that limit the amount of traditional solvents and reduces environmental effects [60]. The extraction principle depends on the effects of enzymatic activity on the cell wall integrity of plants and increases the permeability of the cell membrane, leading to efficient extraction of bioactive compounds. Most enzymes are derived from microbial organisms or different sources, such as plants and animals [61,62]. However, in recent studies, a combination of DES with enzyme activity is used in the so-called DES-based EAE, which is a suitable alternative for polysaccharide extraction from Dendrobium officinale (DOP), where different types of DESs were used. Choline chloride/glycerol-based EAE shows efficient DOP extraction when used with cellulose and pectinase, which also exhibit antioxidant scavenging activities [63].

\section{DES for Extraction of Bioactive Compounds}

Different extraction methods were carried out using many types of DESs to obtain target bioactive compounds from various plants (Table 2). Current trends show that DESs are used to extract bi-compounds, tri-compounds and natural compounds, which cover most secondary metabolic plant materials, such as phenolics, flavonoids, isoflavonoids, terpenoids, alkaloids, anthocyanins, anthraquinones and polysaccharides.

\subsection{Phenolic Compounds}

Phenolic compounds consist of hydroxyl groups connected to an aromatic ring, and the main structure is known as the "phenol structure" [64]. Phenolic compounds are categorized as simple phenol, polyphenol, coumarins and others [65]. These compounds have garnered the interest of researchers in recent years due to their highly beneficial and significant results. Through various bioactivity assays, the benefits of these compounds include antibacterial, antioxidant and potential anti-cancer effects $[64,66]$. Studies used DES compounds for phenolic material extraction as an alternative to traditional alcoholic solvents [67]. For example, extraction of phenolic compounds by DES from Carthamus tinctorius uses proline:malic acid (PMH) and 25\% of water; the method efficiently extracted 
phenolics, such as hydroxysafflor yellow A (HSYA) and cartormin compounds [68]. Extraction of phenolic metabolites using DES and conventional organic solvents has been compared; using choline chloride:oxalic acids with $25 \%$ water from grape skin was highly effective for extraction [69]. The preparation of DES consists of choline chloride:citric acid at molar ratio of 2:1 with 30\% water added to investigate the extraction of total polyphenolic compounds from grape pomace. Compared with traditional extraction systems, extraction using DES had higher total extraction yield $\left(2892.07 \mathrm{mg} . \mathrm{g}^{-1}\right)$ and good bioactivity results, such as antioxidant activity by ORAC method and in vitro cytotoxicity by antiproliferative assay [70].

\subsection{Flavonoid Compounds}

Flavonoids are members of phenolic compounds with carbon as the main structure [71]. Flavonoids exhibit antioxidant, anti-microbial and antitumor properties associated with bladder cancer $[72,73]$. Traditional extraction of flavonoids has relied on different methods and conventional solvents due to difficulty in dissolving in aqueous solvents with time and amount loss. Recently, DES has been used as an alternative solvent; the method exhibits increased yield of flavonoids and is time and cost saving [74,75]. In addition, choline chloride:levulinic acid as DES can efficiently extract flavonoid glycosides and a glycones from Platycladi cacumen (myricitrin, quercitrin, amentoflavone, hinokiflavone) [76]. In 2015, bioactive compounds, such as rutin, were extracted from Sophora japonica by using 20 kinds of DES prepared from choline chloride and different HBD. The excellent properties of DES indicate that they have the potential to be used as solvents for extraction of rutin [30].

\subsection{Alkaloids Compounds}

Alkaloids are organic compounds that comprise complexes with a nitrogenous ring structure and are available in nature. These compounds exhibit important biological activities, such as anticancer [77]. Alkaloids are considered the most effective secondary metabolic material in Chinese medicinal plants and can be extracted using conventional and green solvents [78,79]. Alkaloid extraction by DES results in three different types of bioactive alkaloids from Berberidis radix. Choline chloride:levulinic acid and betaine:levulinic acid have higher alkaloid extractability compared with traditional solvents [80]. Three alkaloid compounds were extracted by choline chloride:fructose with $35 \%$ water from Crinum powellii bulb plant; this solvent had higher amounts of total alkaloids extracted than conventional solvents such as ethanol or methanol [81]. Furthermore, DES, which includes lactic acid:glucose:water (LGH) solvent, was used for alkaloid bio-extraction from Larrea cuneifolia; the extract showed significant antimicrobial activity against Candida albicans [82].

\subsection{Other Bioactive Compounds}

Several methods have improved the extraction of total anthocyanin compounds from herbal plants [83]. Ten different types of DES were screened for extraction of total anthocyanin; the citric acid:D-(+)-maltose as solvent exhibited $80 \%$ higher extraction yield than conventional methanol aqueous solvents. Moreover, the crude extract exerted antioxidant activity [84]. Bioactive components of plant polysaccharides possess bio-activities, such as anti-cancer, anti-virus and anti-oxidation $[85,86]$. The crude polysaccharide extract from Camellia oleifera abel was obtained using 17 types of DES as solvents; the optimal solvent system comprised choline chloride:ethylene glycol with 30\% water, leading to a total yield of $152.37 \mathrm{mg} . \mathrm{g}^{-1}$, which is higher than that of the control using aqueous extraction. Antioxidant activity was also markedly noticeable [87].

\section{Biological Application of Plant Extracts Obtained Using DES}

Table 2 summarizes the bioactivity effects including anti-oxidation, antibacterial and Antitumor activities of compounds extracted from plants by DES. 


\subsection{Antioxidant Activity}

Studies in Table 2 used different antioxidant activity assays, such as DPPH free radical scavenging assay, ferric reducing antioxidant power (FRAP), hydroxyl radical $(\% \mathrm{OH})$ scavenging activity and ABTS. In the crude extraction of phenolic and flavonoid compounds from marjoram, the DES mixture used comprised lactic acid:glycine:water in the molar ratio of 3:1:3, which resulted in higher yields of phenolic and flavonoid compounds than $60 \%$ aqueous ethanol as solvent; the extract was subjected to DPPH assay and exhibited antiradical activity of $1950 \mu \mathrm{mol}$ DPPH per gram dry weight [24]. Higher amounts of phenolic compounds were extracted from Rosmarinus officinalis L. when using choline chloride:lactic acid (1:3) compared with conventional $100 \%$ ethanol as solvent. After identifying the phenolic compounds in the extract, the ferric reducing antioxidant property was measured via FRAP assay and had a value of $183.82 \mathrm{mM}$ trolox/g), which is higher than that obtained using ethanol extract [88]. Hence, different bioactive compounds with high antioxidation properties can be extracted from plants by using green solvents instead of traditional solvents. Given that plants contain high amounts of polyphenols, they may also have high antiradical scavenger activity due to molecular interaction between plant and DES; the reaction will lead to reduced oxidative degradation due to insufficient movement of solute molecules [23,89].

\subsection{Antibacterial Activity}

Bacterial growth inhibition assessment is a widely used method because it is inexpensive and time-saving process (one or two days). The effects of plant extracts obtained by DES extraction on bacterial growth were studied. Phycocyanin bioactive compound was extracted from Arthrospira platensis. The solvent system of xylose:glycerol in a 1:1 ratio was the most effective for extraction phycocyanin among five different DESs tested. The compound with the most efficient activity was determined using agar well diffusion, and the extract demonstrated strong activity against Escherichia coli and Enterobacter aerogenes, which showed wells with 17 and $16 \mathrm{~mm}$ diameter, respectively [90]. Other studies investigated the effects of the total polyphenol content extracted using malic acid:glucose:glycerol (1:1:1) from Punica granatum $\mathrm{L}$. The antimicrobial activity of the extract was determined against Gram-positive Staphylococcus aureus; $90 \%$ inhibition was observed at $0.7 \mathrm{mg} . \mathrm{mL}^{-1}$ concentration. The result differed when ascorbic acid activity was used as control. This result confirms the interaction of polyphenols with the cell membrane of microorganisms, leading to microbial cell death or enzyme inhibition [91]. Flavonoids extracted from Scutellariae radix by ultrasound-assisted DES have been shown to possess equal anti-inflammatory activities to traditional solvents through inhibiting the release of nitric oxide production with the increase of extract concentration [92].

\subsection{Antitumor Activity}

Some researchers have discovered the cytotoxicity activity of medicinal plants extracted by DES in vitro by using MTS assay. Polyphenolic bioactive compounds were extracted from grape pomace by using choline chloride:citric acid (2:1) and tested against HeLa (cervical cancer) and MCF-7 (breast cancer) cell lines, with cell availability of $37.61 \%$ on cells lines at $5 \%(v / v)$ within $72 \mathrm{~h}$. The compound extracted from olive pomace by using the same protocol showed clear results in the in vitro cytotoxicity (MTS) assay, with cell availability of $12.19 \%$ on cells lines at $5 \%(v / v)$ within $72 \mathrm{~h}$ [70]. Ginsenoside bioactive compound extracted from ginseng by using ternary DES (GPS-5) glycerol:1-proline:sucrose (9:4:1) as alternative solvent. Extract showed anti-tumor activity against human colorectal cancer cell lines at $58 \mu \mathrm{g} \mathrm{mL}$; meanwhile, DES had no cytotoxic effects as determined via MTT assay [84]. All the above biological activities are presented in (Figure 2). 
Table 2. Summary the application of the DES in medicinal plants extraction.

\begin{tabular}{|c|c|c|c|c|c|c|c|c|c|c|}
\hline \multirow{2}{*}{ Plant Name } & \multicolumn{2}{|c|}{ DES Type } & \multicolumn{3}{|c|}{ Sample } & \multicolumn{3}{|c|}{ Method of Extraction/Bioactive Compounds } & \multirow{2}{*}{ Mode of Action } & \multirow{2}{*}{ Ref } \\
\hline & Composition & M.R & Parts & Amount & Technique & Type & Yield \% & Instrumental & & \\
\hline $\begin{array}{l}\text { Arthrospira } \\
\text { platensis }\end{array}$ & xylose:glycerol & $1: 1$ & Powder & $30 \mathrm{mg}$ & MAE & Phycocyanin & $85 \mu \mathrm{g} \cdot \mathrm{mL}^{-1}$ & Spectrophotometer & $\begin{array}{l}\text { Antibacterial activity: the phycocyanin fraction } \\
\text { collected which obtained from extraction has activity } \\
\text { against bacteria have been evaluated by agar well } \\
\text { diffusion method with a zone inhibition against } \\
\text { Escherichia coli is ( } 17 \mathrm{~mm} \text { ) and against Enterobacter } \\
\text { aerogenes is (16 } \mathrm{mm}) \text {. } \\
\text { Optimization condition (10 } \mathbf{~ m i n , ~} \mathbf{3 4 8} \mathbf{k}, \mathrm{CCD})\end{array}$ & [90] \\
\hline Averrhoa bilimbi & $\begin{array}{c}\text { choline } \\
\text { chloride:citric } \\
\text { acid } \\
\text { monohydrate }\end{array}$ & $1: 3$ & Powder & $10 \mathrm{mg}$ & $\mathrm{H}$ and $\mathrm{S}$ & $\begin{array}{l}\text { Total phenolic } \\
\text { pectin }\end{array}$ & $\begin{array}{c}1.39 \% \text { Gallic } \\
\text { acid }\end{array}$ & Spectrophotometer & $\begin{array}{l}\text { Antioxidant activity: the plant extracted has activity } \\
\text { was evaluated by two methods: } \\
\text { 1. DPPH free radical scavenging assay with value } \\
\text { percentage ( } 41.64 \% \text { ). } \\
\text { 2. FRAP ferric reducing antioxidant power assay } \\
\quad \text { with value } 1.15 \mathrm{Mm} \text {. } \\
\left.\text { Optimization condition ( } 150 \mathrm{~min}, 80^{\circ} \mathrm{C}, \mathrm{BBD}\right)\end{array}$ & [89] \\
\hline Averrhoa bilmbi & $\begin{array}{c}\text { choline } \\
\text { chloride:citric } \\
\text { acid } \\
\text { monohydrate }\end{array}$ & $1: 3$ & Powder & $1 \mathrm{~g}$ & $\mathrm{H}$ and $\mathrm{S}$ & $\begin{array}{l}\text { Phenolic } \\
\text { pectin }\end{array}$ & $\begin{array}{c}2.41 \% \text { Gallic } \\
\text { acid }\end{array}$ & Spectrophotometer & $\begin{array}{l}\text { Antioxidant activity: the phenolic extracted from } \\
\text { plant by DES has activity was evaluated by } \\
\text { two assays: } \\
\text { 1. Free radical scavenging DPPH assay: with } \\
\text { highest value is ( } 54.76 \%) \text {. } \\
\text { 2. Ferric reducing antioxidant power (FRAP) } \\
\text { assay: with value (1.34 Mm FeSO4). }\end{array}$ & [93] \\
\hline Camellia sinensis & $\begin{array}{l}\text { betaine, } \\
\text { glycerol, and } \\
\text { D-(p)-glucose }\end{array}$ & $4: 20: 1$ & Powder & $100 \mathrm{mg}$ & UAE & Catechins & $100 \mathrm{mg} \cdot \mathrm{g}^{-1}$ & LC-UV & $\begin{array}{l}\text { The extract can be readily used in cosmetic products } \\
\text { or pharmaceutical formulations for skin } \\
\text { Optimization condition }\left(6.5 \mathrm{~min}, 37^{\circ} \mathrm{C}, \mathrm{CCD}\right)\end{array}$ & [94] \\
\hline $\begin{array}{c}\text { Camellia oleifera } \\
\text { Abel. }\end{array}$ & $\begin{array}{l}\text { choline chlo- } \\
\text { ride:ethylene } \\
\text { glycol }\end{array}$ & $1: 2$ & Powder & $0.1 \mathrm{~g}$ & UAE & Polysaccharides & $152.37 \mathrm{mg} . \mathrm{g}^{-1}$ & ELASA & $\begin{array}{l}\text { Antioxidant activity: the purity polysaccharides } \\
\text { extracted by DES has activity was evaluated by } \\
\text { two methods. }\end{array}$ & [87] \\
\hline $\begin{array}{l}\text { Cicer arietinum } \\
\text { L. }\end{array}$ & $\begin{array}{l}\text { choline chlo- } \\
\text { ride:propylene } \\
\text { glycol }\end{array}$ & $1: 1$ & Powder & $50 \mathrm{mg}$ & UAE & $\begin{array}{c}\text { Flavonoid } \\
\text { isoflavones: }\end{array}$ & $7.98 \mathrm{mg}$ QE.g $^{-1}$ & Spectrophotometer & $\begin{array}{l}\text { Antioxidant activity: the extracted by DES was } \\
\text { measured by two methods to determine the } \\
\text { antioxidant ability: } \\
\text { 1. DPPH free radical scavenging activity assay } \\
\text { with clear result at }(13 \%) \text {. } \\
\text { ABTS assay used to determine ability with } \\
\left.\text { result ( } 16 \mu \mathrm{gE} \cdot \mathrm{g}^{-1} \mathrm{CPA}\right) \text {. } \\
\text { Optimization condition }\left(35 \mathrm{~min}, 59^{\circ} \mathrm{C}, \mathrm{BBD}\right)\end{array}$ & [95] \\
\hline
\end{tabular}


Table 2. Cont.

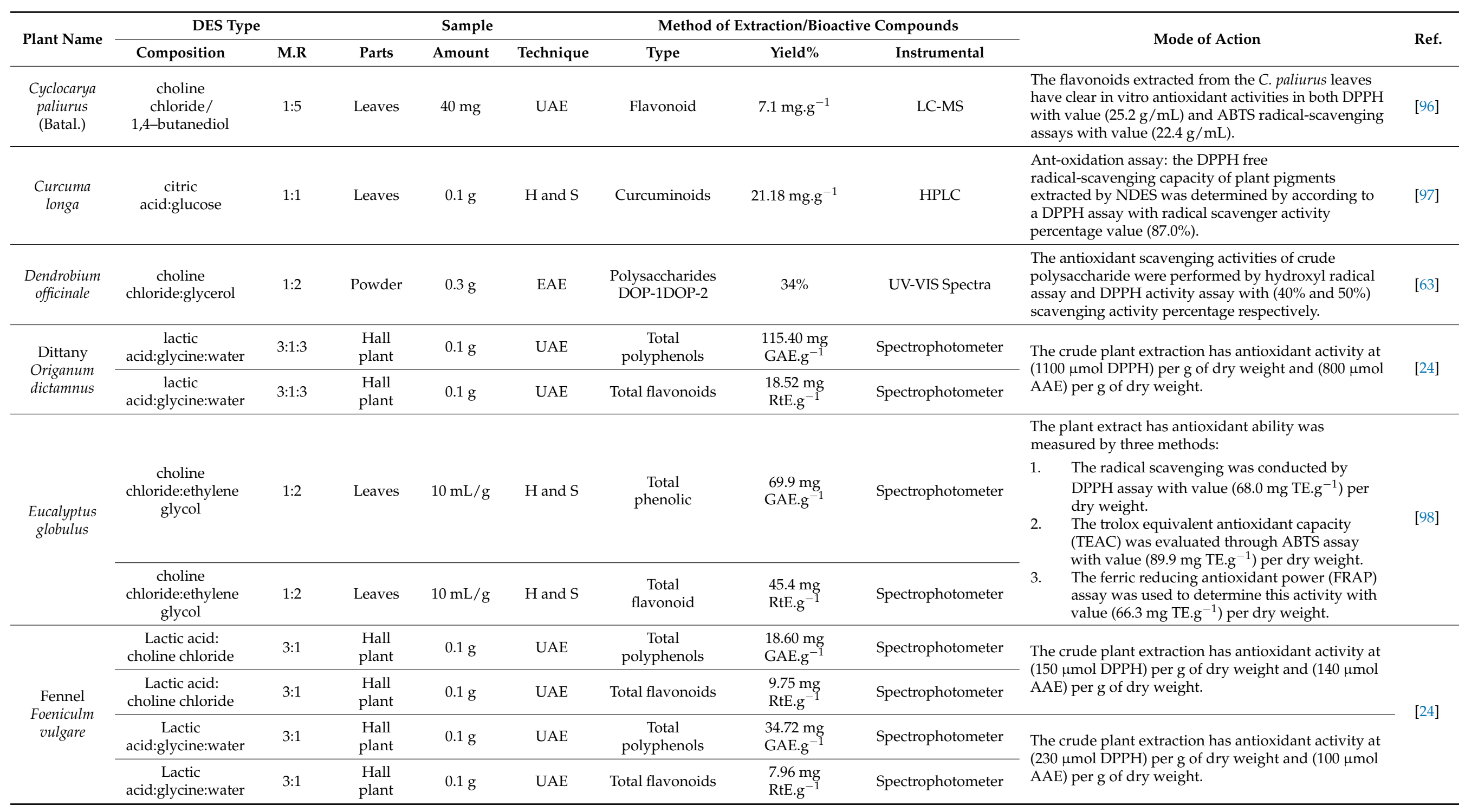


Table 2. Cont.

\begin{tabular}{|c|c|c|c|c|c|c|c|c|c|c|}
\hline \multirow{2}{*}{ Plant Name } & \multicolumn{2}{|c|}{ DES Type } & \multicolumn{3}{|c|}{ Sample } & \multicolumn{3}{|c|}{ Method of Extraction/Bioactive Compounds } & \multirow{2}{*}{ Mode of Action } & \multirow{2}{*}{ Ref. } \\
\hline & Composition & M.R & Parts & Amount & Technique & Type & Yield $\%$ & Instrumental & & \\
\hline & & & & & & & & & $\begin{array}{l}\text { The PAC extracted has antioxidant activity was } \\
\text { measured by: }\end{array}$ & \\
\hline Ginkgo biloba & $\begin{array}{l}\text { choline chlo- } \\
\text { ride:malonic } \\
\quad \text { acid }\end{array}$ & $1: 2$ & Leaves & $100 \mathrm{mg}$ & WBS & $\begin{array}{l}\text { Proanthocyanidin } \\
\text { (PAC) }\end{array}$ & $22.19 \mathrm{mg} \cdot \mathrm{g}^{-1}$ & Spectrophotometer & $\begin{array}{l}\text { 1. Total reduction capability: } \mathrm{IC}_{50} \text { is } \\
\left(53.68 \mu \mathrm{g} \cdot \mathrm{mL}^{-1}\right) \text { and after recovered } \mathrm{IC}_{50} \text { is } \\
\left(52.24 \mu \mathrm{g} \cdot \mathrm{mL}^{-1}\right) \text {. } \\
\text { 2. } \mathrm{DPPH} \text { free radical scavenging capability: } \mathrm{IC}_{50} \text { is } \\
\left(136.71 \mu \mathrm{g} \cdot \mathrm{mL}^{-1}\right) \text { and after recovered } \mathrm{IC}_{50} \text { is } \\
\left(128.38 \mu \mathrm{g} \cdot \mathrm{mL}^{-1}\right) \text {. } \\
\text { 3. } \\
\text { ABTS free radical scavenging capability: } \mathrm{IC}_{50} \text { is } \\
\left(4.77 \mu \mathrm{g} \cdot \mathrm{mL}^{-1}\right) \text { and after recovered } \mathrm{IC}_{50} \text { is } \\
\left(8.06 \mu \mathrm{g} \cdot \mathrm{mL}^{-1}\right) \text {. }\end{array}$ & [99] \\
\hline
\end{tabular}

Optimization condition $\left(53 \mathrm{~min}, 65{ }^{\circ} \mathrm{C}, \mathrm{CCD}\right)$

Antioxidant activity: the plant extracted with DES has activity was measured by two assays with RSM optimization:

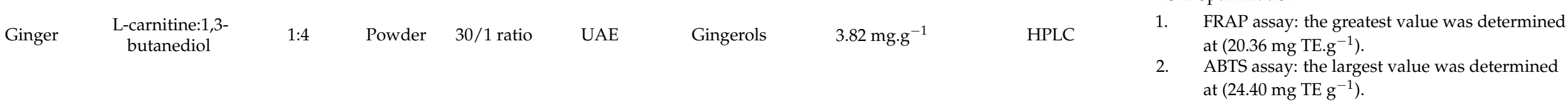

Optimization condition $\left(30 \mathrm{~min}, 50^{\circ} \mathrm{C}, \mathrm{CCD}\right)$

The Total ginsenosides have anti-tumor activity through used Human colorectal cancer cell lines at $(58 \mu \mathrm{mL})$ and the DES had no cytotoxic effects was determined with MTT assay.

Optimization condition $\left(45 \mathrm{~min}, 60^{\circ} \mathrm{C}, \mathrm{CCD}\right)$ 
Table 2. Cont

\begin{tabular}{|c|c|c|c|c|c|c|c|c|c|c|}
\hline \multirow{2}{*}{ Plant Name } & \multicolumn{2}{|c|}{ DES Type } & \multicolumn{3}{|c|}{ Sample } & \multicolumn{3}{|c|}{ Method of Extraction/Bioactive Compounds } & \multirow{2}{*}{ Mode of Action } & \multirow{2}{*}{ Ref. } \\
\hline & Composition & M.R & Parts & Amount & Technique & Type & Yield $\%$ & Instrumental & & \\
\hline \multirow{2}{*}{ Grape skins } & $\begin{array}{l}\text { choline } \\
\text { chloride:malic } \\
\text { acid }\end{array}$ & $1: 1$ & Powder & $0.1 \mathrm{~g}$ & $\begin{array}{l}\text { ultrasonic } \\
\text { bath }\end{array}$ & $\begin{array}{l}\text { Total phenolic } \\
\text { content }\end{array}$ & $91 \mathrm{mg} \cdot \mathrm{g}^{-1}$ & Spectrophotometer & \multirow{2}{*}{$\begin{array}{l}\text { The antioxidant activity of crude extraction is } \\
\text { ( } 371 \mu \text { mol TE) per } g \text { of dry weight was determined by } \\
\text { the oxygen radical absorbance capacity } \\
\text { (ORAC) method. } \\
\text { The choline chloride: malic acid NDES has } \\
\text { antiproliferative activity against MCF-7 and HeLa } \\
\text { cells at } 18 \text { and } 23 \text { cell viability, respectively was }\end{array}$} & \multirow{2}{*}{100} \\
\hline & $\begin{array}{l}\text { choline } \\
\text { chloride:malic } \\
\text { acid }\end{array}$ & $1: 1$ & Powder & $0.1 \mathrm{~g}$ & $\begin{array}{l}\text { ultrasonic } \\
\text { bath }\end{array}$ & $\begin{array}{l}\text { Total } \\
\text { anthocyanin } \\
\text { content }\end{array}$ & $24 \mathrm{mg} \cdot \mathrm{g}^{-1}$ & Spectrophotometer & & \\
\hline Grape skin & $\begin{array}{l}\text { citric acid:D- } \\
(+) \text {-maltose }\end{array}$ & $4: 1$ & Powder & $100 \mathrm{mg}$ & UAE & $\begin{array}{l}\text { Total } \\
\text { anthocyanins } \\
\text { content } \\
\text { (TAC) }\end{array}$ & $63.36 \mathrm{mg} \cdot \mathrm{g}^{-1}$ & Spectrophotometer & $\begin{array}{l}\text { evaluated by WST-1 cell proliferation assay. } \\
\text { The relative TAC extraction with radical scavenging } \\
\text { activity (RSA) at the same level ( } 59 \% \text { per g) of dry } \\
\text { weight by using DPPH assay }\end{array}$ & [101] \\
\hline $\begin{array}{l}\text { Green coffee } \\
\text { beans }\end{array}$ & Glycerol:betaine & $1: 2$ & Powder & $0.4 \mathrm{~g}$ & $\mathrm{H}$ and $\mathrm{S}$ & $\begin{array}{l}\text { Phenolics } \\
\text { (chlorogenic } \\
\text { acids) }\end{array}$ & $7.37 \%$ & HPLC & $\begin{array}{l}\text { The plant extract with phenolics compound has } \\
\text { biochemical activity was determined by In vivo assay } \\
\text { with rats. }\end{array}$ & [102] \\
\hline $\begin{array}{l}\text { Ixora } \\
\text { javanica }\end{array}$ & $\begin{array}{l}\text { choline chlo- } \\
\text { ride:propylen } \\
\text { eglycol }\end{array}$ & $1: 1$ & Flowers & $0.05 \mathrm{~g}$ & UAE & $\begin{array}{l}\text { Total flavonoid } \\
\text { content }\end{array}$ & $\begin{array}{l}13.5 \mathrm{mg} \\
\text { QE.g }\end{array}$ & Spectrophotometer & $\begin{array}{l}\text { Antioxidant activity: The activity of the extract was } \\
\text { determined by its DPPH radical scavenging assay } \\
\text { with highest inhibition value ( } 83 \% \text { ). Tyrosinase } \\
\text { inhibitory activity: The activity of the extract was } \\
\text { determined by Mushroom tyrosinase solution with } \\
\text { highest inhibition value ( } 49 \% \text { ). } \\
\left.\text { Optimization condition ( } 5 \text { min, } 57^{\circ} \mathrm{C}, \mathrm{CCD}\right)\end{array}$ & {$[103]$} \\
\hline \multirow{3}{*}{$\begin{array}{c}\text { Lemon } \\
\text { waste peels }\end{array}$} & glycerol:choline & $3: 1$ & Powder & $0.1 \mathrm{~g}$ & UAE & Total & $53.76 \mathrm{mg}$ & Spectrophotometer & \multirow{3}{*}{$\begin{array}{l}\text { Antioxidant activity: the plant extracted with DES has } \\
\text { antioxidant activity was measured by two assays: } \\
\text { 1. Antiradical activity } \mathrm{A}_{\mathrm{AR}} \text { at }(230 \mu \mathrm{mol} \mathrm{DPPH}) \\
\text { per g of dry weight. } \\
\text { 2. Reducing power } \mathrm{P}_{\mathrm{R}} \text { at }(65 \mu \mathrm{mol} \mathrm{AAE}) \text { per g of } \\
\text { dry weight. }\end{array}$} & \multirow{3}{*}[104]{} \\
\hline & chloride & & & & & polyphenols & GAE.g & & & \\
\hline & $\begin{array}{l}\text { glycerol:choline } \\
\text { chloride }\end{array}$ & $3: 1$ & Powder & $0.1 \mathrm{~g}$ & UAE & Total flavonoid & $\begin{array}{l}19.42 \mathrm{mg} \\
\text { RtE.g }\end{array}$ & Spectrophotometer & & \\
\hline \multirow{2}{*}{$\begin{array}{l}\text { Mangosteen } \\
\text { pericarp }\end{array}$} & $\begin{array}{c}\text { citric } \\
\text { acid:alanine }\end{array}$ & $1: 1$ & Powder & $2.5 \mathrm{~g}$ & $\begin{array}{l}\text { Batch } \\
\text { system }\end{array}$ & $\begin{array}{l}\text { Total phenolic } \\
\text { content }\end{array}$ & $179.54 \mathrm{mg} \cdot \mathrm{g}^{-1}$ & Spectrophotometer & \multirow{2}{*}{$\begin{array}{l}\text { The total crude plant of extract has Antioxidant } \\
\text { Activity measured by DPPH free radical scavenger } \\
\text { assay with IC50 inhibition percentage is }\left(46 \mu \mathrm{g} \cdot \mathrm{mL}^{-1}\right) \text {. }\end{array}$} & \multirow{2}{*}{ [59] } \\
\hline & $\begin{array}{c}\text { citric } \\
\text { acid:alanine }\end{array}$ & $1: 1$ & Powder & $2.5 \mathrm{~g}$ & $\begin{array}{l}\text { Batch } \\
\text { system }\end{array}$ & Xanthone & $\begin{array}{c}24.87 \\
\mathrm{mg} \cdot \mathrm{g}^{-1}\end{array}$ & Spectrophotometer & & \\
\hline \multirow{2}{*}{$\begin{array}{l}\text { Marjoram } \\
\text { Origanum } \\
\text { majorana }\end{array}$} & $\begin{array}{c}\text { lactic } \\
\text { acid:glycine:water }\end{array}$ & 3:1:3 & $\begin{array}{l}\text { Hall } \\
\text { plant }\end{array}$ & $0.1 \mathrm{~g}$ & UAE & $\begin{array}{c}\text { Total } \\
\text { polyphenols }\end{array}$ & $\begin{array}{l}137.36 \mathrm{mg} \\
\text { GAE.g }^{-1}\end{array}$ & Spectrophotometer & \multirow{2}{*}{$\begin{array}{l}\text { The crude plant extraction has antioxidant activity at } \\
\text { (1950 } \mu \text { mol DPPH) per g of dry weight and }(900 \mu \mathrm{mol} \\
\text { AAE) per g of dry weight. }\end{array}$} & \multirow{2}{*}{ [24] } \\
\hline & $\begin{array}{c}\text { lactic } \\
\text { acid:glycine:water }\end{array}$ & 3:1:3 & $\begin{array}{l}\text { Hall } \\
\text { plant }\end{array}$ & $0.1 \mathrm{~g}$ & UAE & Total flavonoids & $\begin{array}{l}21.70 \mathrm{mg} \\
\text { RtE.g }\end{array}$ & Spectrophotometer & & \\
\hline
\end{tabular}


Table 2. Cont

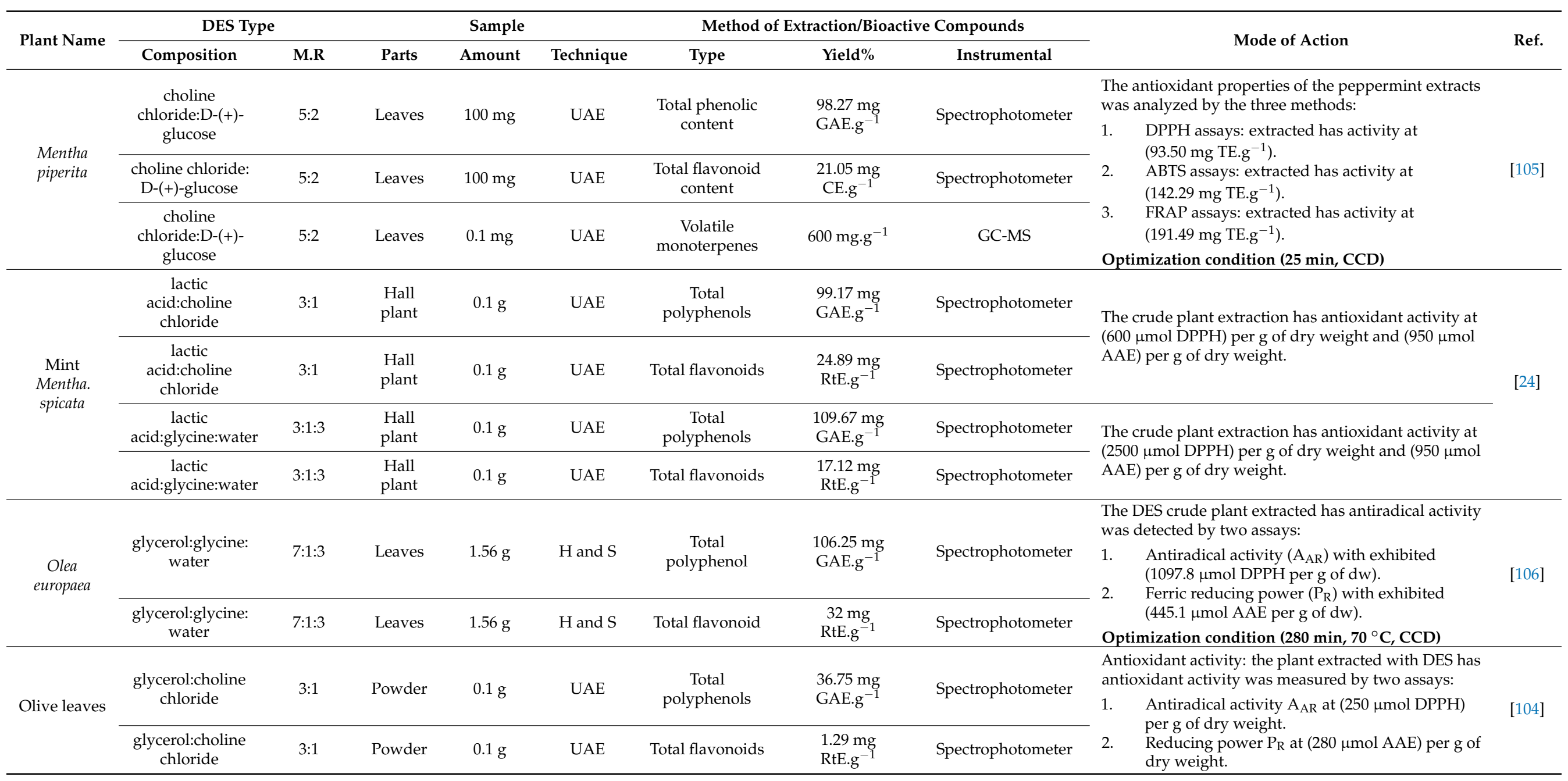


Table 2. Cont

\begin{tabular}{|c|c|c|c|c|c|c|c|c|c|c|}
\hline \multirow{2}{*}{ Plant Name } & \multicolumn{2}{|c|}{ DES Type } & \multicolumn{3}{|c|}{ Sample } & \multicolumn{3}{|c|}{ Method of Extraction/Bioactive Compounds } & \multirow{2}{*}{ Mode of Action } & \multirow{2}{*}{ Ref. } \\
\hline & Composition & M.R & Parts & Amount & Technique & Type & Yield $\%$ & Instrumental & & \\
\hline $\begin{array}{l}\text { Olive } \\
\text { pomace }\end{array}$ & $\begin{array}{l}\text { choline } \\
\text { chloride:citric } \\
\text { acid }\end{array}$ & $2: 1$ & Powder & $0.5 \mathrm{~g}$ & UAE & $\begin{array}{l}\text { Total } \\
\text { polyphenolic }\end{array}$ & $\begin{array}{l}645.99 \mathrm{mg} / \mathrm{kg} \\
\text { per dw }\end{array}$ & HPLC & $\begin{array}{l}\text { Antioxidant capacity of polyphenolic extract was } \\
\text { evaluated through Oxygen radical absorbance } \\
\text { capacity assay (ORAC) with value } \\
(453.10 \mu \text { molTE g-1 dw). Antiproliferative activity of } \\
\text { polyphenolic extract was evaluated by in vitro } \\
\text { cytotoxicity (MTS) assay with cell availability } 12.19 \% \\
\text { on cells lines at } 5 \%(v / v) \text { through } 72 \mathrm{~h} \text {. }\end{array}$ & [70] \\
\hline \multirow{3}{*}{$\begin{array}{l}\text { Onion solid } \\
\text { wastes }\end{array}$} & $\begin{array}{l}\text { glycerol:choline } \\
\text { chloride }\end{array}$ & $3: 1$ & Powder & $0.1 \mathrm{~g}$ & UAE & $\begin{array}{l}\text { Total } \\
\text { nolls }\end{array}$ & $82.94 \mathrm{mg}$ & Spectrophotometer & $\begin{array}{l}\text { Antioxidant activity: the plant extracted with DES has } \\
\text { antioxidant activity was measured by two assays: }\end{array}$ & \\
\hline & & & & & & & & & $\begin{array}{l}\text { Antiradical activity } A_{\mathrm{AR}} \text { at }(618.55 \mu \mathrm{mol} \mathrm{DPPH}) \\
\text { per g of dry weight. }\end{array}$ & [104] \\
\hline & $\begin{array}{l}\text { glycerol:choline } \\
\text { chloride }\end{array}$ & $3: 1$ & Powder & $0.1 \mathrm{~g}$ & UAE & Total flavonoid & $\begin{array}{l}80.68 \mathrm{mg} \\
\text { RtE.g }\end{array}$ & Spectrophotometer & $\begin{array}{l}\text { 2. Reducing power } P_{\mathrm{R}} \text { at }(700.79 \mu \mathrm{mol} \text { AAE }) \text { per } g \\
\text { of dry weight. }\end{array}$ & \\
\hline \multirow[t]{2}{*}{ Onion peels } & $\begin{array}{l}\text { choline chlo- } \\
\text { ride:urea:water }\end{array}$ & 1:2:4 & Powder & $1 \mathrm{~g}$ & $\mathrm{H}$ and $\mathrm{S}$ & Phenolics & $\begin{array}{l}64.23 \mathrm{mg} \\
\text { GAE.g }\end{array}$ & Spectrophotometer & $\begin{array}{l}\text { Antioxidant activity: the phenolic extract by DES and } \\
\text { through in vitro Ferric Reducing Antioxidant Power } \\
\text { (FRAP) assay has activity in highest PR value } \\
1457.19 \mu \text { mol AAE g of dry weight }\end{array}$ & \multirow[t]{2}{*}{107} \\
\hline & $\begin{array}{l}\text { choline chlo- } \\
\text { ride:sucrose:water }\end{array}$ & $4: 1: 8$ & Powder & $1 \mathrm{~g}$ & MAE & Phenolics & $\begin{array}{l}48 \mathrm{mg} \\
\text { GAE.g }\end{array}$ & Spectrophotometer & $\begin{array}{l}\text { Antioxidant activity: the phenolic extract by DES and } \\
\text { through In vitro Radical Scavenging Activity (AAR) } \\
\text { assay has activity in highest value } 79.81 \% \text {. }\end{array}$ & \\
\hline $\begin{array}{l}\text { Orange } \\
\text { peelwaste }\end{array}$ & $\begin{array}{l}\text { choline chlo- } \\
\text { ride:ethylene } \\
\text { glycol }\end{array}$ & $1: 4$ & Powder & $0.5 \mathrm{~g}$ & SLE & $\begin{array}{l}\text { Total phenolic } \\
\text { content }\end{array}$ & $\begin{array}{l}3.61 \mathrm{mg} \\
\text { GAE.g }\end{array}$ & Spectrophotometer & $\begin{array}{l}\text { The Orange peel waste extracted has antioxidant } \\
\text { activity was estimated by DPPH free radical } \\
\text { scavenger assay obtained IC } 50\left(30.6 \mu \mathrm{g} \cdot \mathrm{mL}^{-1}\right) \text {. }\end{array}$ & [2] \\
\hline $\begin{array}{l}\text { Picea abies } \\
\text { bark }\end{array}$ & $\begin{array}{l}\text { choline } \\
\text { chloride:lactic } \\
\text { acid }\end{array}$ & $1: 1$ & Powder & $1 \mathrm{~g}$ & $\mathrm{H}$ and $\mathrm{S}$ & $\begin{array}{l}\text { Total phenolic } \\
\text { content }\end{array}$ & $100 \mathrm{mg}^{-1}$ & Spectrophotometer & $\begin{array}{l}\text { The bark crude extraction has free radical scavenging } \\
\text { activity RSA }(16 \%) \text { at } 30 \text { min and }(16.59 \%) \text { after } 30 \\
\text { min by DPPH assay }\end{array}$ & [108] \\
\hline \multirow{2}{*}{ Propolis } & $\begin{array}{l}\text { choline } \\
\text { chloride:tartaric } \\
\text { acid }\end{array}$ & $2: 1$ & Powder & $1 \mathrm{~g}$ & UAE & Flavonoid & $46.0 \mathrm{mg} \mathrm{CE} . \mathrm{g}^{-1}$ & Spectrophotometer & \multirow{2}{*}{$\begin{array}{l}\text { Antioxidant activity: the plant extracted has } \\
\text { antioxidant capacity was evaluated by DPPH } \\
\text { scavenging ability assay with } 62.2 \text { IC } 50 \text { in } \mu \mathrm{g} \cdot \mathrm{mL}^{-1} \text {. } \\
\text { Optimization condition ( } 10 \mathrm{~min}, \mathrm{CCD})\end{array}$} & \multirow{2}{*}[109]{} \\
\hline & $\begin{array}{l}\text { choline } \\
\text { chloride:tartaric } \\
\text { acid }\end{array}$ & $2: 1$ & Powder & $1 \mathrm{~g}$ & UAE & Tannins & $\begin{array}{l}2.40 \mathrm{mg} \\
\text { CE.g }\end{array}$ & Spectrophotometer & & \\
\hline
\end{tabular}


Table 2. Cont.

\begin{tabular}{|c|c|c|c|c|c|c|c|c|c|c|}
\hline \multirow{2}{*}{ Plant Name } & \multicolumn{2}{|l|}{ DES Type } & \multicolumn{3}{|c|}{ Sample } & \multicolumn{3}{|c|}{ Method of Extraction/Bioactive Compounds } & \multirow{2}{*}{ Mode of Action } & \multirow{2}{*}{ Ref. } \\
\hline & Composition & M.R & Parts & Amount & Technique & Type & Yield \% & Instrumental & & \\
\hline \multirow{3}{*}{$\begin{array}{l}\text { Punica } \\
\text { granatum L. }\end{array}$} & $\begin{array}{c}\text { malic } \\
\text { acid:sucrose }\end{array}$ & $1: 1$ & Powder & $1 \mathrm{~g}$ & IRE & $\begin{array}{l}\text { Total } \\
\text { polyphenol } \\
\text { content }\end{array}$ & $\begin{array}{l}75 \mathrm{mg} \\
\text { GAE.g }\end{array}$ & Spectrophotometer & \multirow{3}{*}{$\begin{array}{l}\text { Antiradical activity: the extracted polyphenols was } \\
\text { evaluated by the free radical scavenging activity } \\
\text { DPPH assay with ( } 339 \mu \mathrm{MTE} \cdot \mathrm{g}^{-1} \text { of DM). } \\
\text { Antioxidant activity: the extracted polyphenols was } \\
\text { evaluated by phosphomolybdenum reduction assay } \\
\left.\text { with ( } 45 \mathrm{mg} \text { AA eq.mL } \mathrm{m}^{-1}\right) \text {. } \\
\text { Antimicrobial activity: the extracted polyphenols by } \\
\text { DES was estimated against the bacterial gram+ } \\
\text { Staphylococcus aureus at } 0.7 \mathrm{mg} / \mathrm{mL} \text { concentration with } \\
\text { inhibition result }(90 \%) \text {. } \\
\text { Antimicrobial activity: the extracted polyphenols by } \\
\text { DES was estimated against the bacterial negative, } \\
\text { Escherichia coli at } 0.7 \mathrm{mg} / \mathrm{mL} \text { concentration with } \\
\text { inhibition result }(90 \%) \text {. }\end{array}$} & \multirow{3}{*}{ [91] } \\
\hline & $\begin{array}{c}\text { malic } \\
\text { acid:glucose:glycerol }\end{array}$ & $1: 1$ & Powder & $1 \mathrm{~g}$ & IRE & $\begin{array}{l}\text { Total } \\
\text { polyphenol } \\
\text { content }\end{array}$ & $\begin{array}{l}152 \mathrm{mg} \\
\text { GAE.g }\end{array}$ & Spectrophotometer & & \\
\hline & $\begin{array}{c}\text { glucose:tartaric } \\
\text { acid }\end{array}$ & $1: 1$ & Powder & $1 \mathrm{~g}$ & IRE & $\begin{array}{c}\text { Total } \\
\text { polyphenol } \\
\text { content }\end{array}$ & 90 mg GAE.g ${ }^{-1}$ & Spectrophotometer & & \\
\hline \multirow{2}{*}{ Rice straw } & $\begin{array}{l}\text { lactic } \\
\text { acid:choline } \\
\text { chloride }\end{array}$ & $5: 1$ & Powder & $\begin{array}{l}5 \% \text { solids } \\
\text { loading }\end{array}$ & $\begin{array}{l}\text { Incubation } \\
\text { and } \\
\text { agitation }\end{array}$ & Lignin & $68.1 \mathrm{mg} \cdot \mathrm{g}^{-1}$ & Spectrophotometer & $\begin{array}{l}\text { The crude cellulase enzyme has activity }(13 \mathrm{U} / \mathrm{mL}) \text { at } \\
0.5 \% \text { of NDES concentrations was measured using } \\
\text { filter paper assay method. }\end{array}$ & [110] \\
\hline & $\begin{array}{l}\text { choline } \\
\text { chloride:malic } \\
\text { acid }\end{array}$ & $1: 1$ & Powder & $\begin{array}{l}5 \% \text { solid } \\
\text { loading }\end{array}$ & Incubation & Lignin & $8.1 \mathrm{mg} \cdot \mathrm{g}^{-1}$ & Spectrophotometer & $\begin{array}{l}\text { The acidic green solvent has antimicrobial growth } \\
\text { activity against Clavispora NRRL Y-50464 when } \\
\text { measured at } 660 \mathrm{~nm} \text { through } 24 \mathrm{~h} \text {. }\end{array}$ & [111] \\
\hline \multirow{2}{*}{$\begin{array}{l}\text { Rosmarinus } \\
\text { officinalis }\end{array}$} & $\begin{array}{l}\text { glycerol:choline } \\
\text { chloride }\end{array}$ & $1: 2$ & Leaves & 150 & UAE & $\begin{array}{l}\text { Total phenolic } \\
\text { content }\end{array}$ & $\begin{array}{l}22.53 \mathrm{mg} \\
\text { GAE.g }\end{array}$ & Spectrophotometer & $\begin{array}{l}\text { Antioxidant activity: the final plant extracted by DES } \\
\text { has activity was measured by DPPH free radical } \\
\left.\text { photometric assay with value ( } 155.83 \text { mMtrolox. }{ }^{-1}\right) \text {. }\end{array}$ & \multirow[b]{2}{*}{ [88] } \\
\hline & $\begin{array}{l}\text { lactic } \\
\text { acid:choline } \\
\text { chloride }\end{array}$ & $1: 3$ & Leaves & 150 & UAE & $\begin{array}{l}\text { Total phenolic } \\
\text { content }\end{array}$ & $\begin{array}{l}59.85 \mathrm{mg} \\
\text { GAE.g }\end{array}$ & Spectrophotometer & $\begin{array}{l}\text { Antioxidant activity: the final plant extracted by DES } \\
\text { has activity was measured by Ferric reducing } \\
\text { antioxidant property (FRAP assay) with value } \\
\left(183.82 \text { mMtrolox. }{ }^{-1}\right) \text {. }\end{array}$ & \\
\hline \multirow{4}{*}{$\begin{array}{l}\text { Sage } \\
\text { Salvia } \\
\text { officinali }\end{array}$} & $\begin{array}{c}\text { lactic } \\
\text { acid:glycine:water }\end{array}$ & $3: 1: 3$ & $\begin{array}{l}\text { Hall } \\
\text { plant }\end{array}$ & $0.1 \mathrm{~g}$ & UAE & $\begin{array}{c}\text { Total } \\
\text { polyphenols }\end{array}$ & $\begin{array}{l}114.92 \mathrm{mg} \\
\text { GAE.g }^{-1}\end{array}$ & Spectrophotometer & \multirow{2}{*}{$\begin{array}{l}\text { The crude plant extraction has antioxidant activity at } \\
(2294 \mu \mathrm{mol} \text { DPPH) per g of dry weight and }(950 \mu \mathrm{mol} \\
\text { AAE) per g of dry weight. }\end{array}$} & \multirow{4}{*}{ [24] } \\
\hline & $\begin{array}{c}\text { lactic } \\
\text { acid:glycine:water }\end{array}$ & $3: 1: 3$ & $\begin{array}{l}\text { Hall } \\
\text { plant }\end{array}$ & $0.1 \mathrm{~g}$ & UAE & Total flavonoids & $\begin{array}{l}24.29 \text { mg } \\
\text { RtE.g }{ }^{-1}\end{array}$ & Spectrophotometer & & \\
\hline & $\begin{array}{c}\text { lactic } \\
\text { acid:choline:chloride }\end{array}$ & $3: 1$ & $\begin{array}{l}\text { Hall } \\
\text { plant }\end{array}$ & $0.1 \mathrm{~g}$ & UAE & $\begin{array}{c}\text { Total } \\
\text { polyphenols }\end{array}$ & $\begin{array}{c}100.90 \mathrm{mg} \\
\text { RtE.g }\end{array}$ & Spectrophotometer & \multirow{2}{*}{$\begin{array}{l}\text { The crude plant extraction has antioxidant activity at } \\
(1000 \mu \mathrm{mol} \text { DPPH) per } \mathrm{g} \text { of dry weight and } \\
(1041 \mu \mathrm{mol} \text { AAE) per g of dry weight. }\end{array}$} & \\
\hline & $\begin{array}{c}\text { lactic } \\
\text { acid:choline:chloride }\end{array}$ & $3: 1$ & $\begin{array}{l}\text { Hall } \\
\text { plant }\end{array}$ & $0.1 \mathrm{~g}$ & UAE & Total flavonoids & $\begin{array}{l}23.56 \mathrm{mg} \\
\text { RtE.g }\end{array}$ & Spectrophotometer & & \\
\hline
\end{tabular}


Table 2. Cont

\begin{tabular}{|c|c|c|c|c|c|c|c|c|c|c|}
\hline \multirow{2}{*}{ Plant Name } & \multicolumn{2}{|l|}{ DES Type } & \multicolumn{3}{|c|}{ Sample } & \multicolumn{3}{|c|}{ Method of Extraction/Bioactive Compounds } & \multirow{2}{*}{ Mode of Action } & \multirow{2}{*}{ Ref. } \\
\hline & Composition & M.R & Parts & Amount & Technique & Type & Yield \% & Instrumental & & \\
\hline \multirow{3}{*}{$\begin{array}{l}\text { Satureja } \\
\text { thymbra }\end{array}$} & $\begin{array}{l}\text { glycerol:tri- } \\
\text { sodium } \\
\text { citrate. }\end{array}$ & $15: 1$ & Powder & $36.2 \mathrm{~mL} / \mathrm{g}$ & $\mathrm{H}$ and $\mathrm{S}$ & Total polyphenol & $\begin{array}{l}186.95 \mathrm{mg} \\
\text { GAE.g }^{-1}\end{array}$ & Spectrophotometer & $\begin{array}{l}\text { The antiradical activity (AAR) of plant crude extracted } \\
\text { was evaluated by the DPPH probe with result } \\
(705.16 \mu \text { mol DPPH g dw) and ferric reducing power } \\
\left(P_{R}\right) \text { activity with result }(695.96 \mu \text { mol AAE g dw). }\end{array}$ & \multirow{3}{*}{112} \\
\hline & $\begin{array}{l}\text { glycerol:sodium } \\
\text { acetate } \\
\text { trihydrate }\end{array}$ & $3: 1$ & Powder & $36.2 \mathrm{~mL} / \mathrm{g}$ & $\mathrm{H}$ and $\mathrm{S}$ & Total polyphenol & $\begin{array}{l}185.19 \mathrm{mg} \\
\text { GAE.g }\end{array}$ & Spectrophotometer & $\begin{array}{l}\text { The antiradical activity (AAR) of plant crude extracted } \\
\text { was evaluated by the DPPH probe with result } \\
(1270.15 \mu \mathrm{mol} \text { DPPH g dw) and ferric reducing power } \\
\left(\mathrm{P}_{\mathrm{R}}\right) \text { activity with result }(535.09 \mu \mathrm{mol} \text { AAE g dw). }\end{array}$ & \\
\hline & $\begin{array}{l}\text { glycerol:choline } \\
\text { chloride }\end{array}$ & $3: 1$ & Powder & $36.2 \mathrm{~mL} / \mathrm{g}$ & $\mathrm{H}$ and $\mathrm{S}$ & Total polyphenol & $\begin{array}{l}171.48 \mathrm{mg} \\
\text { GAE.g }\end{array}$ & Spectrophotometer & $\begin{array}{l}\text { The antiradical activity (AAR) of plant crude extracted } \\
\text { was evaluated by the DPPH probe with result } \\
(1268.90 \mu \text { mol DPPH g dw) and ferric reducing power } \\
\left(\mathrm{P}_{\mathrm{R}}\right) \text { activity with result }(1193.44 \mu \mathrm{mol} \text { AAE g dw). } \\
\left.\text { Optimization condition ( } 200 \mathrm{~min}, \mathbf{8 0}^{\circ} \mathrm{C}, \mathrm{BBD}\right)\end{array}$ & \\
\hline $\begin{array}{c}\text { Sea } \\
\text { buckthorn } \\
\text { leaves }\end{array}$ & $\begin{array}{l}\text { 1,4- } \\
\text { butanediol:choline } \\
\text { chloride }\end{array}$ & $3: 1$ & Leaves & $1 \mathrm{~g}$ & MAE & Flavonoids & $20.82 \mathrm{mg} \cdot \mathrm{g}^{-1}$ & HPLC & $\begin{array}{l}\text { The flavonoid extraction from leave has antioxidant } \\
\text { activity was measured by DPPH assay with } \mathrm{IC}_{50} \\
\text { value }\left(0.074 \mathrm{mg} \text {. } \mathrm{mL}^{-1}\right) \text { and } \mathrm{ABTS} \text { radical-scavenging } \\
\text { activity assay with value }\left(0.662 \mathrm{mmol} \cdot \mathrm{g}^{-1} \text { trolox) }\right. \\
\text { while reducing power assay }\left(\mathrm{P}_{\mathrm{R}}\right) \text { with } \mathrm{IC}_{50} \text { value } \\
\left(0.127 \mathrm{mg} \cdot \mathrm{mL}^{-1}\right) \text {. } \\
\text { Optimization condition ( }\left(17 \mathrm{~min}, \mathbf{6 4}{ }^{\circ} \mathrm{C} \text {, BBD) }\right.\end{array}$ & [54] \\
\hline \multirow{3}{*}{$\begin{array}{l}\text { Sophora } \\
\text { japonica }\end{array}$} & \multirow{3}{*}{$\begin{array}{l}\text { choline } \\
\text { chloride: } \\
\text { triethylene } \\
\text { glycol }\end{array}$} & \multirow{3}{*}{$1: 4$} & \multirow{3}{*}{ Powder } & \multirow{3}{*}{$1 \mathrm{~g}$} & \multirow{3}{*}{$\begin{array}{c}\text { Water } \\
\text { bath and } \\
\text { stirring }\end{array}$} & \multirow{3}{*}{ Rutin } & \multirow{3}{*}{$279.8 \mathrm{mg} \cdot \mathrm{g}^{-1}$} & \multirow{3}{*}{ HPLC } & $\begin{array}{l}\text { The rutin extracted by DES has antioxidant activity } \\
\text { through measured by three methods: }\end{array}$ & \multirow{3}{*}{113} \\
\hline & & & & & & & & & $\begin{array}{l}\text { 1. The radical scavenging activity (RSA) of rutin is } \\
\left(5.68 \mu \mathrm{g} \cdot \mathrm{mL}^{-1}\right) \text { by DPPH radical scavenging } \\
\text { assay. } \\
\text { The radical scavenging activity (RSA) of rutin is } \\
\left(0.19 \mu \mathrm{g} \cdot \mathrm{mL}^{-1}\right) \text { by Superoxide radical } \\
\text { scavenging assay. } \\
\text { 3. The radical scavenging activity (RSA) of rutin is } \\
\left(0.28 \mu \mathrm{g} \cdot \mathrm{mL}^{-1}\right) \text { by Hydroxyl radical } \\
\text { scavenging assay. }\end{array}$ & \\
\hline & & & & & & & & & Optimization condition $\left(23 \mathrm{~min}, 70^{\circ} \mathrm{C}, \mathrm{BBD}\right)$ & \\
\hline Soybean oil & $\begin{array}{l}\text { choline chlo- } \\
\text { ride:ascorbic } \\
\text { acid }\end{array}$ & $2: 1$ & Oil & $0.10 \mathrm{~g}$ & UALLME & $\begin{array}{c}\text { (TBHQ) } \\
\text { tert- } \\
\text { Butylhydroquinone }\end{array}$ & $73.07 \mathrm{mg} \cdot \mathrm{kg}^{-1}$ & HPLC & $\begin{array}{l}\text { The TBHQ extracted from oil sample by Vc-based DES } \\
\text { showed a protection ability for antioxidant activity }\end{array}$ & [114] \\
\hline
\end{tabular}


Table 2. Cont.

\begin{tabular}{|c|c|c|c|c|c|c|c|c|c|c|}
\hline \multirow{2}{*}{ Plant Name } & \multicolumn{2}{|c|}{ DES Type } & \multicolumn{3}{|c|}{ Sample } & \multicolumn{3}{|c|}{ Method of Extraction/Bioactive Compounds } & \multirow{2}{*}{ Mode of Action } & \multirow{2}{*}{ Ref. } \\
\hline & Composition & M.R & Parts & Amount & Technique & Type & Yield \% & Instrumental & & \\
\hline \multirow{5}{*}{$\begin{array}{l}\text { Spent coffee } \\
\text { grounds }\end{array}$} & $\begin{array}{l}\text { 1,6-hexanediol: } \\
\text { choline chloride }\end{array}$ & $2: 1$ & Powder & $50 \mathrm{mg}$ & UAE & $\begin{array}{c}\text { Total } \\
\text { chlorogenic }\end{array}$ & $\begin{array}{c}19.6 \mathrm{mg} \\
\text { 3-CQA.g }{ }^{-1}\end{array}$ & UHPLC & \multirow{5}{*}{$\begin{array}{l}\text { The plant extracted by DES has antioxidant capacity } \\
\text { was determined by three methods: } \\
\text { 1. DPPH assay: used to evaluated the antioxidant } \\
\text { activity at } 21.2 \mathrm{mg} \text { TE. } \mathrm{g}^{-1} \\
\text { 2. FRAP assay: used to evaluated the antioxidant } \\
\text { activity at } 31.3 \mathrm{mg} \text { TE. } \mathrm{g}^{-1} \\
\text { ABTS assay: used to evaluated the antioxidant } \\
\text { activity at } 30.7 \mathrm{mg} \text { TE. } .^{-1} \\
\left.\text { Optimization condition ( } 45 \mathrm{~min}, 60^{\circ} \mathrm{C}, \mathrm{CCD}\right)\end{array}$} & \multirow{5}{*}{ [115] } \\
\hline & & & & & & & & & & \\
\hline & $\begin{array}{l}1,6- \\
\text { hexanediol:choline } \\
\text { chloride }\end{array}$ & $2: 1$ & Powder & $50 \mathrm{mg}$ & UAE & $\begin{array}{l}\text { Total phenolic } \\
\text { content }\end{array}$ & $\begin{array}{l}15.1 \mathrm{mg} \\
\text { GAE.g }^{-1}\end{array}$ & Spectrophotometer & & \\
\hline & \multirow{2}{*}{$\begin{array}{l}1,6- \\
\text { hexanediol:choline } \\
\text { chloride }\end{array}$} & \multirow[t]{2}{*}{$2: 1$} & \multirow{2}{*}{ Powder } & \multirow{2}{*}{$50 \mathrm{mg}$} & \multirow[t]{2}{*}{ UAE } & \multirow{2}{*}{$\begin{array}{l}\text { Total flavonoid } \\
\text { content }\end{array}$} & \multirow{2}{*}{$\begin{array}{l}18.7 \mathrm{mg} \\
\mathrm{CE} \cdot \mathrm{g}^{-1}\end{array}$} & \multirow[t]{2}{*}{ Spectrophotometer } & & \\
\hline & & & & & & & & & & \\
\hline \multirow{5}{*}{$\begin{array}{l}\text { Spent filter } \\
\text { coffee }\end{array}$} & \multirow{2}{*}{$\begin{array}{l}\text { glycerol:choline } \\
\text { chloride }\end{array}$} & \multirow{2}{*}{$3: 1$} & \multirow{2}{*}{ Powder } & \multirow{2}{*}{$0.1 \mathrm{~g}$} & \multirow{2}{*}{ UAE } & \multirow{2}{*}{$\begin{array}{l}\text { Total } \\
\text { polyphenols }\end{array}$} & \multirow{2}{*}{$\begin{array}{l}22.59 \mathrm{mg} \\
\text { GAE.g }\end{array}$} & \multirow{2}{*}{ Spectrophotometer } & $\begin{array}{l}\text { Antioxidant activity: the plant extracted with DES has } \\
\text { antioxidant activity was measured by two assays: }\end{array}$ & \multirow{5}{*}{104} \\
\hline & & & & & & & & & 1. $\quad$ Antiradical activity $\mathrm{A}_{\mathrm{AR}}$ at $(80 \mu \mathrm{mol} \mathrm{DPPH})$ & \\
\hline & $\begin{array}{l}\text { glycerol:choline } \\
\text { chloride }\end{array}$ & $3: 1$ & Powder & $0.1 \mathrm{~g}$ & UAE & Total flavonoid & $\begin{array}{l}0.57 \mathrm{mg} \\
\text { RtE.g } \\
\end{array}$ & Spectrophotometer & $\begin{array}{l}\text { 2. Reducing power } P_{\mathrm{R}} \text { at }(140 \mu \mathrm{mol} \mathrm{AAE}) \text { per } \mathrm{g} \text { of } \\
\text { dry weight. }\end{array}$ & \\
\hline & $\begin{array}{l}\text { glycerol:sodium- } \\
\text { potassium }\end{array}$ & 5:1:4 & Powder & $0.1 \mathrm{~g}$ & UAE & $\begin{array}{c}\text { Total } \\
\text { polyphenols }\end{array}$ & $\begin{array}{l}11.58 \mathrm{mg} \\
{\text { GAE } \mathrm{g}^{-1}}^{-1}\end{array}$ & Spectrophotometer & \multirow{2}{*}{$\begin{array}{l}\text { Antioxidant activity: the plant extracted with DES has } \\
\text { antioxidant activity was measured by two assays: } \\
\text { 1. Antiradical activity } \mathrm{A}_{\mathrm{AR}} \text { at }(60 \mu \mathrm{mol} \mathrm{DPPH}) \\
\text { per g of dry weight. } \\
\text { 2. Reducing power } \mathrm{P}_{\mathrm{R}} \text { at }(290 \mu \mathrm{mol} \text { AAE }) \text { per g of } \\
\text { dry weight. }\end{array}$} & \\
\hline & $\begin{array}{l}\text { glycerol:sodium- } \\
\text { potassium } \\
\text { tartrate:water }\end{array}$ & 5:1:4 & Powder & $0.1 \mathrm{~g}$ & UAE & Total flavonoid & $\begin{array}{l}1.42 \mathrm{mg} \\
\text { RtE.g }\end{array}$ & Spectrophotometer & & \\
\hline Vitis vinifera, & $\begin{array}{l}\text { 1,2- } \\
\text { Propanediol- } \\
\text { choline } \\
\text { chloride-water }\end{array}$ & 1:1:1 & Powder & $100 \mathrm{~g}$ & $\begin{array}{l}\text { agitation } \\
\text { and } \\
\text { magnetic } \\
\text { stirrer }\end{array}$ & Resveratrol & $10.982 \mu \mathrm{g} \cdot \mathrm{mL}^{-1}$ & UPLC-UV & $\begin{array}{l}\text { MTT cytotoxicity assay used to determine the activity } \\
\text { of } 2 \% \text { NADES/PCW THP- } 1 \text { and HUVEC cell line with } \\
\text { the results showed that at concentration exhibited } \\
\text { high deleterious impact on respective viability of } 71 \\
\text { and } 85 \% \text {, respectively. }\end{array}$ & [116] \\
\hline
\end{tabular}


Table 2. Cont

\begin{tabular}{|c|c|c|c|c|c|c|c|c|c|c|}
\hline \multirow{2}{*}{ Plant Name } & \multicolumn{2}{|c|}{ DES Type } & \multicolumn{3}{|c|}{ Sample } & \multicolumn{3}{|c|}{ Method of Extraction/Bioactive Compounds } & \multirow{2}{*}{ Mode of Action } & \multirow{2}{*}{ Ref. } \\
\hline & Composition & M.R & Parts & Amount & Technique & Type & Yield\% & Instrumental & & \\
\hline \multirow{4}{*}{ Wheat bran } & glycerol:choline & $3: 1$ & Powder & $0.1 \mathrm{~g}$ & UAE & Total & $17.8 \mathrm{mg}$ & Spectrophotometer & $\begin{array}{l}\text { Antioxidant activity: the plant extracted with DES has } \\
\text { antioxidant activity was measured by two assays: }\end{array}$ & \multirow{4}{*}{ [104] } \\
\hline & $\begin{array}{l}\text { glycerol:choline } \\
\text { chloride }\end{array}$ & $3: 1$ & Powder & $0.1 \mathrm{~g}$ & UAE & Total flavonoids & $\begin{array}{l}7.27 \mathrm{mg} \\
\text { RtE.g } \\
\end{array}$ & Spectrophotometer & $\begin{array}{l}\text { 2. Reducing power } \mathrm{P}_{\mathrm{R}} \text { at }(25 \mu \mathrm{mol} \mathrm{AAE}) \text { per g of } \\
\text { dry weight. }\end{array}$ & \\
\hline & $\begin{array}{l}\text { glycerol:sodium- } \\
\text { potassium } \\
\text { tartrate:water }\end{array}$ & $5: 1: 4$ & Powder & $0.1 \mathrm{~g}$ & UAE & $\begin{array}{c}\text { Total } \\
\text { polyphenols }\end{array}$ & $\begin{array}{l}1.53 \mathrm{mg}^{-1} \\
\text { GAE.g }\end{array}$ & Spectrophotometer & \multirow{2}{*}{$\begin{array}{l}\text { Antioxidant activity: the plant extracted with DES has } \\
\text { antioxidant activity was measured by two assays: } \\
\text { 1. Antiradical activity } \mathrm{A}_{\mathrm{AR}} \text { at }(50 \mu \mathrm{mol} \mathrm{DPPH}) \\
\text { per g of dry weight. } \\
\text { 2. Reducing power } \mathrm{P}_{\mathrm{R}} \text { at }(75 \mu \mathrm{mol} \mathrm{AAE}) \text { per g of } \\
\text { dry weight. }\end{array}$} & \\
\hline & $\begin{array}{l}\text { glycerol:sodium- } \\
\text { potassium } \\
\text { tartrate:water }\end{array}$ & $5: 1: 4$ & Powder & $0.1 \mathrm{~g}$ & UAE & Total flavonoids & $\begin{array}{l}0.79 \mathrm{mg} \\
\text { RtE.g }\end{array}$ & Spectrophotometer & & \\
\hline
\end{tabular}




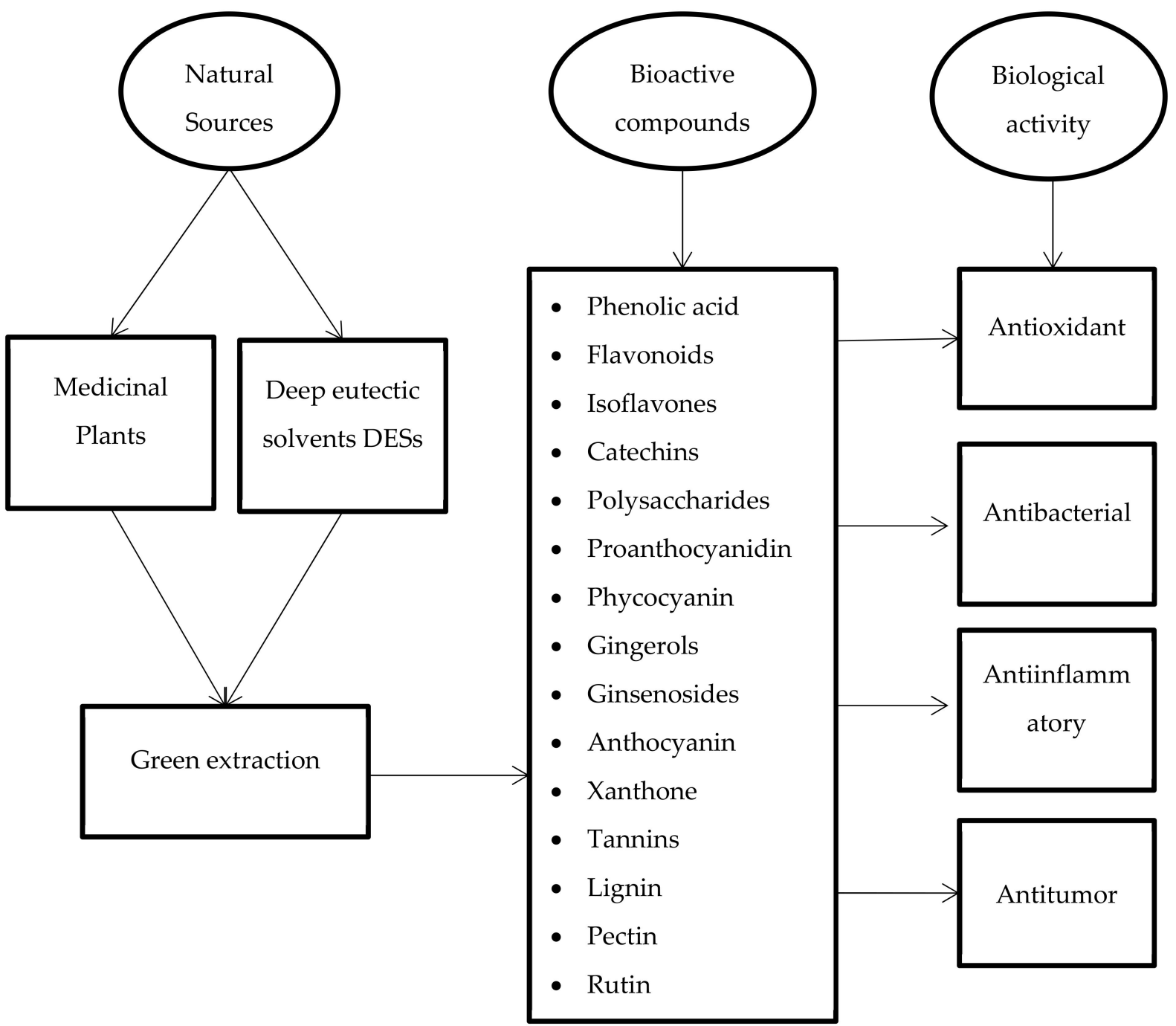

Figure 2. Steps for the green extraction media of beneficial bioactive compounds.

\section{DES as Eco-Friendly Medium of Extraction}

Eco-friendly solvents should have characteristically low toxicity and acceptable high levels of biodegradability; scholars have studied these characteristics for types of DES and most studies that have biodegradability assessment for DESs are to be considered "easily biodegradable" [43,117,118]. Most DES mixtures have good environmental aspects such as choline chloride $(\mathrm{ChCl})$, the main compound used in different DESs [119]. NADES have similar eco-friendly characteristics as well as these constituents being synthesized by natural components and having no draw back effect [120]. All mixtures are not expensive, have good recyclability and are compatible with industry products, such as pharmaceutical and cosmetic products [42].

In a previous work, the closed bottle test method was used to assess the biodegradability for three types of choline chloride-based DES in wastewater aqueous media containing microorganisms [121]. The same method was used to determine the biodegradability of 20 types of DES. These solvents included amine-based DES, sugar-based DES, alcoholbased DES and acid-based DES; the solvent was observed within 28 days and measured for oxygen demand every seven days. Amine-based DES exhibited the highest value of biodegradability, whereas acid-based DES had the lowest value. DES have higher 
biodegradability than the conventional solvents tested. The primary reason could be the permeability of the cell membrane in different ways [30].

Many authors determined that DESs and NDESs have low toxicity characteristic for human health and the environment [43,122]. The variation of DESs' toxicity is dependent on the main structure compounds [123].

\section{Conclusions and Future Perspectives}

Using DES as medium for extraction of bioactive compounds from medicinal plants is superior to methods utilizing conventional solvents and is a green and environmentfriendly approach. The green properties of DESs are due to their low toxicity, ecofriendliness, biodegradability, shorter time and wider ability to solubilize compounds with different polarities. In this regard, DESs have been increasingly applied in green extraction of plants. Toxicity investigations are needed, and several factors, such as molar ratio mixture, water content and temperature as well as physiochemical properties should be explored. These factors will increase the yield and lead to broad and different bioactivities. Nonetheless, additional experimental works should be carried out using DESs as potential extractive agents, and their toxicity should be evaluated. Given their potential use as antioxidants, antibacterial agents, new therapeutic agents and in vitro activity, further investigations for alternative extraction using DESs that are safe for human consumption need to be explored before they are applied in the food or pharmaceutical industries.

Author Contributions: Conceptualization, A.S.D. and M.F.A.B.; methodology, A.S.D. and S.F.S.; data validation, M.F.A.B. and S.F.S.; formal analysis, A.S.D. and M.A.; resources, A.S.D.; data curation, A.S.D. and M.F.A.B.; writing—original draft preparation, A.S.D.; writing—review and editing, A.S.D., M.F.A.B., M.A. and S.F.S.; visualization, A.S.D.; supervision, M.F.A.B., M.A. and S.F.S.; project administration, M.F.A.B.; funding acquisition, A.F.M.H. and A.M. All authors have read and agreed to the published version of the manuscript.

Funding: Ministry of Higher Education of Malaysia (MoHE) for the research grant under Fundamental Research Grant Scheme (FRGS) Vot: K099 (FRGS/1/2018/WAB01/UTHM/02/1), Industrial Grant (Vot M024) by UWG Marketing \& Distributors Sdn. Bhd.

Institutional Review Board Statement: The study was not involving humans or animals.

Informed Consent Statement: The study did not involve humans.

Acknowledgments: The authors would like to thank the Ministry of Higher Education of Malaysia (MoHE) for the research grant under Fundamental Research Grant Scheme (FRGS) Vot: K099 (FRGS/1/2018/WAB01/UTHM/02/1), Industrial Grant (Vot M024) by UWG Marketing \& Distributors Sdn. Bhd as well as Universiti Tun Hussein Onn Malaysia (UTHM) for the use of laboratory facilities and assistance.

Conflicts of Interest: The authors declare no conflict of interest.

\section{Abbreviations}

$\begin{array}{ll}\text { AAE } & \text { Ascorbic acid equivalents } \\ \mathrm{A}_{\mathrm{AR}} & \text { Antiradical activity } \\ \mathrm{BBD} & \text { Box-Behnken design } \\ \mathrm{BI} & \text { Bacterial inhibition } \\ \mathrm{CCD} & \text { Central composite design } \\ \mathrm{CHCL} & \text { Choline chloride } \\ \mathrm{COS} & \text { Conventional organic solvents } \\ \text { DES } & \text { Deep eutectic solvents } \\ \text { DPPH } & \text { 2,2-Diphenyl-1-picrylhydrazyl } \\ \text { EAE } & \text { Enzyme-assisted extraction } \\ \text { ELISA } & \text { Enzyme-linked immunosorbent assay } \\ \text { FRAP } & \text { Ferric reducing antioxidant power } \\ \text { GAE } & \text { Gallic acid equivalents }\end{array}$




$\begin{array}{ll}\text { HBA } & \text { Hydrogen-bond acceptor } \\ \text { HBD } & \text { Hydrogen-bond donor } \\ \text { H and S } & \text { Heating and stirring } \\ \text { HPLC } & \text { High performance liquid chromatography } \\ \text { ILs } & \text { Ionic liquids } \\ \text { IRE } & \text { Infra extraction } \\ \text { LGH } & \text { Lactic acid-glucose } \\ \text { MAE } & \text { Microwave-assisted extraction } \\ \text { NADES } & \text { Natural deep eutectic solvent } \\ \text { MBC } & \text { Minimum bacterial concentration } \\ \text { MIC } & \text { Minimum inhibitory concentration } \\ \text { M.R } & \text { Molar ratio } \\ \text { NPCE } & \text { Negative pressure cavitation extraction } \\ \text { PHWE } & \text { Pressurized hot water extraction } \\ \text { PLE } & \text { Pressurized liquid extraction } \\ \text { PR } & \text { Reducing power } \\ \text { RtE } & \text { Rutin equivalents } \\ \text { SLE } & \text { Super liquid extraction } \\ \text { SWE } & \text { Subcritical water extraction } \\ \text { UAE } & \text { Ultrasound-assisted extraction } \\ \text { UV-VIS } & \text { Ultraviolet-visible spectrophotometry } \\ \text { WBS } & \text { Water bath system } \\ \text { UALLME } & \text { Ultrasound assisted liquid liquid microextraction } \\ & \end{array}$

\section{References}

1. Cory, H.; Passarelli, S.; Szeto, J.; Tamez, M.; Mattei, J. The Role of Polyphenols in Human Health and Food Systems: A Mini-Review. Front. Nutr. 2018, 5, 87. [CrossRef] [PubMed]

2. Ozturk, B.; Parkinson, C.; Gonzalez-Miquel, M. Extraction of polyphenolic antioxidants from orange peel waste using deep eutectic solvents. Sep. Purif. Technol. 2018, 206, 1-13. [CrossRef]

3. Mbous, Y.P.; Hayyan, M.; Hayyan, A.; Wong, W.F.; Hashim, M.A.; Looi, C.Y. Applications of deep eutectic solvents in biotechnology and bioengineering-Promises and challenges. Biotechnol. Adv. 2016, 35, 105-134. [CrossRef]

4. Jablonský, M.; Škulcová, A.; Malvis, A.; Šima, J. Extraction of value-added components from food industry based and agro-forest biowastes by deep eutectic solvents. J. Biotechnol. 2018, 282, 46-66. [CrossRef]

5. Benvenutti, L.; Bortolini, D.G.; Nogueira, A.; Zielinski, A.A.F.; Alberti, A. Effect of addition of phenolic compounds recovered from apple pomace on cider quality. LWT 2018, 100, 348-354. [CrossRef]

6. Karpińska-Tymoszczyk, M. The effect of antioxidants, packaging type and frozen storage time on the quality of cooked turkey meatballs. Food Chem. 2014, 148, 276-283. [CrossRef]

7. Agostini-Costa, T.d.S.; Bizzo, H.R.D.S.; Gimenes, M.A.R.F.V. Secondary Metabolites, Chromatography and Its Applications; InTech: London, UK, 2012; pp. 131-132.

8. Ventura, S.; Silva, F.; Quental, M.J.; Mondal, D.; Freire, M.; Coutinho, J.A.P. Ionic-Liquid-Mediated Extraction and Separation Processes for Bioactive Compounds: Past, Present, and Future Trends. Chem. Rev. 2017, 117, 6984-7052. [CrossRef]

9. Bart, H.-J. Extraction of Natural Products from Plants-An Introduction. In Industrial Scale Natural Products Extraction; Wiley-VCH Verlag GmbH \& Co. KGaA: Weinheim, Germany, 2011; p. 16.

10. Djande, C.H.; Piater, L.; Steenkamp, P.; Madala, N.; Dubery, I. Differential extraction of phytochemicals from the multipurpose tree, Moringa oleifera, using green extraction solvents. S. Afr. J. Bot. 2018, 115, 81-89. [CrossRef]

11. Wang, M.; Wang, J.; Zhang, Y.; Xia, Q.; Bi, W.; Yang, X.; Chen, D.D.Y. Fast environment-friendly ball mill-assisted deep eutectic solvent-based extraction of natural products. J. Chromatogr. A 2016, 1443, 262-266. [CrossRef] [PubMed]

12. Bart, H.-J. Extraction of natural products from plants-An introduction. In Industrial Scale Natural Products Extraction; Wiley-VCH Verlag GmbH \& Co. KGaA: Weinheim, Germany, 2011; pp. 1-25.

13. Tang, B.; Zhang, H.; Row, K.H. Application of deep eutectic solvents in the extraction and separation of target compounds from various samples. J. Sep. Sci. 2015, 38, 1053-1064. [CrossRef] [PubMed]

14. Cseri, L.; Szekely, G. Towards cleaner PolarClean: Efficient synthesis and extended applications of the polar aprotic solvent methyl 5-(dimethylamino)-2-methyl-5-oxopentanoate. Green Chem. 2019, 21, 4178-4188. [CrossRef]

15. Meng, X.; Pu, Y.; Li, M.; Ragauskas, A.J. A biomass pretreatment using cellulose-derived solvent Cyrene. Green Chem. 2020, 22, 2862-2872. [CrossRef]

16. Hayyan, M.; Mbous, Y.P.; Looi, C.Y.; Wong, W.F.; Hayyan, A.; Salleh, Z.; Mohd-Ali, O. Natural deep eutectic solvents: Cytotoxic profile. SpringerPlus 2016, 5, 913. [CrossRef]

17. Liu, Y.; Friesen, J.B.; McAlpine, J.B.; Lankin, D.C.; Chen, S.-N.; Pauli, G.F. Natural Deep Eutectic Solvents: Properties, Applications, and Perspectives. J. Nat. Prod. 2018, 81, 679-690. [CrossRef] [PubMed] 
18. Gorke, J.; Srienc, F.; Kazlauskas, R. Toward advanced ionic liquids. Polar, enzyme-friendly solvents for biocatalysis. Biotechnol. Bioprocess Eng. 2010, 15, 40-53. [CrossRef] [PubMed]

19. Carvalho, P.; Guedes, R.; Bronze, M.; Faustino, C.; Ribeiro, M. Design of a New Gemini Lipoaminoacid with Immobilized Lipases Based on an Eco-Friendly Biosynthetic Process. Catalysts 2021, 11, 164. [CrossRef]

20. Morais, T.; Cotas, J.; Pacheco, D.; Pereira, L. Seaweeds Compounds: An Ecosustainable Source of Cosmetic Ingredients? Cosmetics 2021, 8, 8. [CrossRef]

21. Alshammari, O.A.O.; Almulgabsagher, G.A.A.; Ryder, K.S.; Abbott, A.P. Effect of solute polarity on extraction efficiency using deep eutectic solvents. Green Chem. 2021, 23, 5097-5105. [CrossRef]

22. Benedetto, A.; Galla, H.-J. Overview of the "Ionic Liquids meet Biomolecules" session at the 19th international IUPAB and 11th EBSA congress. Biophys. Rev. 2017, 9, 279-281. [CrossRef]

23. Dai, Y.; Rozema, E.; Verpoorte, R.; Choi, Y.H. Application of natural deep eutectic solvents to the extraction of anthocyanins from Catharanthus roseus with high extractability and stability replacing conventional organic solvents. J. Chromatogr. A 2016, 1434, 50-56. [CrossRef]

24. Bakirtzi, C.; Triantafyllidou, K.; Makris, D.P. Novel lactic acid-based natural deep eutectic solvents: Efficiency in the ultrasoundassisted extraction of antioxidant polyphenols from common native Greek medicinal plants. J. Appl. Res. Med. Aromat. Plants 2016, 3, 120-127. [CrossRef]

25. Zainal-Abidin, M.H.; Hayyan, M.; Hayyan, A.; Jayakumar, N.S. New horizons in the extraction of bioactive compounds using deep eutectic solvents: A review. Anal. Chim. Acta 2017, 979, 1-23. [CrossRef] [PubMed]

26. Huang, J.; Guo, X.; Xu, T.; Fan, L.; Zhou, X.; Wu, S. Ionic deep eutectic solvents for the extraction and separation of natural products. J. Chromatogr. A 2019, 1598, 1-19. [CrossRef]

27. Choi, Y.H.; Verpoorte, R. Green solvents for the extraction of bioactive compounds from natural products using ionic liquids and deep eutectic solvents. Curr. Opin. Food Sci. 2019, 26, 87-93. [CrossRef]

28. Mena-García, A.; Ruiz-Matute, A.I.; Soria, A.C.; Sanz, M.L. Green techniques for extraction of bioactive carbohydrates. TrAC Trends Anal. Chem. 2019, 119, 115612. [CrossRef]

29. Abbott, A.P.; Boothby, D.; Capper, G.; Davies, D.; Rasheed, R.K. Deep Eutectic Solvents Formed between Choline Chloride and Carboxylic Acids: Versatile Alternatives to Ionic Liquids. J. Am. Chem. Soc. 2004, 126, 9142-9147. [CrossRef] [PubMed]

30. Zhao, B.-Y.; Xu, P.; Yang, F.-X.; Wu, H.; Zong, M.-H.; Lou, W.-Y. Biocompatible Deep Eutectic Solvents Based on Choline Chloride: Characterization and Application to the Extraction of Rutin from Sophora japonica. ACS Sustain. Chem. Eng. 2015, 3, $2746-2755$. [CrossRef]

31. Dai, Y.; van Spronsen, J.; Witkamp, G.-J.; Verpoorte, R.; Choi, Y.H. Natural deep eutectic solvents as new potential media for green technology. Anal. Chim. Acta 2013, 766, 61-68. [CrossRef] [PubMed]

32. AlOmar, M.; Hayyan, M.; AlSaadi, M.; Akib, S.; Hayyan, A.; Hashim, M.A. Glycerol-based deep eutectic solvents: Physical properties. J. Mol. Liq. 2015, 215, 98-103. [CrossRef]

33. Hayyan, A.; Hashim, M.A.; Hayyan, M.; Mjalli, F.S.; AlNashef, I. A new processing route for cleaner production of biodiesel fuel using a choline chloride based deep eutectic solvent. J. Clean. Prod. 2013, 65, 246-251. [CrossRef]

34. Smith, E.L.; Abbott, A.; Ryder, K. Deep Eutectic Solvents (DESs) and Their Applications. Chem. Rev. 2014, 114, 11060-11082. [CrossRef]

35. Zhang, Q.; Vigier, K.D.O.; Royer, S.; Jerome, F. Deep eutectic solvents: Syntheses, properties and applications. Chem. Soc. Rev. 2012, 41, 7108-7146. [CrossRef]

36. Nahar, Y.; Thickett, S.C. Greener, Faster, Stronger: The Benefits of Deep Eutectic Solvents in Polymer and Materials Science. Polymers 2021, 13, 447. [CrossRef]

37. D'Agostino, C.; Harris, R.; Abbott, A.; Gladden, L.F.; Mantle, M.D. Molecular motion and ion diffusion in choline chloride based deep eutectic solvents studied by $1 \mathrm{H}$ pulsed field gradient NMR spectroscopy. Phys. Chem. Chem. Phys. 2011, 13, 21383-21391. [CrossRef] [PubMed]

38. Patyar, P.; Ali, A.; Malek, N.I. Experimental and theoretical excess molar properties of aqueous choline chloride based deep eutectic solvents. J. Mol. Liq. 2020, 324, 114340. [CrossRef]

39. Pandey, A.; Rai, R.; Pal, M.; Pandey, S. How polar are choline chloride-based deep eutectic solvents? Phys. Chem. Chem. Phys. 2014, 16, 1559-1568. [CrossRef] [PubMed]

40. Pandey, A.; Pandey, S. Solvatochromic Probe Behavior within Choline Chloride-Based Deep Eutectic Solvents: Effect of Temperature and Water. J. Phys. Chem. B 2014, 118, 14652-14661. [CrossRef] [PubMed]

41. Cunha, S.C.; Fernandes, J.O. Extraction techniques with deep eutectic solvents. TrAC Trends Anal. Chem. 2018, 105, 225-239. [CrossRef]

42. Abbott, A.P.; Harris, R.; Ryder, K.; D’Agostino, C.; Gladden, L.F.; Mantle, M.D. Glycerol eutectics as sustainable solvent systems. Green Chem. 2010, 13, 82-90. [CrossRef]

43. Khandelwal, S.; Tailor, Y.K.; Kumar, M. Deep eutectic solvents (DESs) as eco-friendly and sustainable solvent/catalyst systems in organic transformations. J. Mol. Liq. 2016, 215, 345-386. [CrossRef]

44. Obst, M.; König, B. Organic Synthesis without Conventional Solvents. Eur. J. Org. Chem. 2018, 2018, 4213-4232. [CrossRef]

45. Chen, Y.; Mu, T. Revisiting greenness of ionic liquids and deep eutectic solvents. Green Chem. Eng. 2021, 2, 174-186. [CrossRef] 
46. Vinatoru, M.; Mason, T.J.; Calinescu, I. Ultrasonically assisted extraction (UAE) and microwave assisted extraction (MAE) of functional compounds from plant materials. TrAC Trends Anal. Chem. 2017, 97, 159-178. [CrossRef]

47. Ashokkumar, M. Applications of ultrasound in food and bioprocessing. Ultrason. Sonochemistry 2015, 25, 17-23. [CrossRef]

48. Zhang, L.; Wang, M. Optimization of deep eutectic solvent-based ultrasound-assisted extraction of polysaccharides from Dioscorea opposita Thunb. Int. J. Biol. Macromol. 2017, 95, 675-681. [CrossRef] [PubMed]

49. Hsieh, Y.-H.; Li, Y.; Pan, Z.; Chen, Z.; Lu, J.; Yuan, J.; Zhu, Z.; Zhang, J. Ultrasonication-assisted synthesis of alcohol-based deep eutectic solvents for extraction of active compounds from ginger. Ultrason. Sonochemistry 2019, 63, 104915. [CrossRef]

50. Veggi, P.C.; Martinez, J.; Meireles, M.A.A. Fundamentals of microwave extraction. In Microwave-Assisted Extraction for Bioactive Compounds; Springer: Berlin/Heidelberg, Germany, 2012; pp. 15-52.

51. Araujo, R.G.; Rodríguez-Jasso, R.M.; Ruíz, H.A.; Govea-Salas, M.; Pintado, M.; Aguilar, C.N. Recovery of bioactive components from avocado peels using microwave-assisted extraction. Food Bioprod. Process. 2021, 127, 152-161. [CrossRef]

52. Belwal, T.; Ezzat, S.M.; Rastrelli, L.; Bhatt, I.D.; Daglia, M.; Baldi, A.; Devkota, H.P.; Orhan, I.E.; Patra, J.K.; Das, G.; et al. A critical analysis of extraction techniques used for botanicals: Trends, priorities, industrial uses and optimization strategies. TrAC Trends Anal. Chem. 2018, 100, 82-102. [CrossRef]

53. Li, Y.; Radoiu, M.; Fabiano-Tixier, A.-S.; Chemat, F. From laboratory to industry: Scale-up, quality, and safety consideration for microwave-assisted extraction. In Microwave-Assisted Extraction for Bioactive Compounds; Springer: Berlin/Heidelberg, Germany, 2012; pp. 207-229.

54. Cui, Q.; Liu, J.-Z.; Wang, L.-T.; Kang, Y.-F.; Meng, Y.; Jiao, J.; Fu, Y.-J. Sustainable deep eutectic solvents preparation and their efficiency in extraction and enrichment of main bioactive flavonoids from sea buckthorn leaves. J. Clean. Prod. 2018, 184, 826-835. [CrossRef]

55. Zhang, D.-Y.; Zu, Y.-G.; Fu, Y.-J.; Luo, M.; Wang, W.; Gu, C.-B.; Zhao, C.; Jiao, J.; Efferth, T. Enzyme pretreatment and negative pressure cavitation extraction of genistein and apigenin from the roots of pigeon pea [Cajanus cajan (L.) Millsp.] and the evaluation of antioxidant activity. Ind. Crop. Prod. 2012, 37, 311-320. [CrossRef]

56. Ameer, K.; Shahbaz, H.; Kwon, J.-H. Green Extraction Methods for Polyphenols from Plant Matrices and Their Byproducts: A Review. Compr. Rev. Food Sci. Food Saf. 2017, 16, 295-315. [CrossRef]

57. Li, L.; Liu, J.-Z.; Luo, M.; Wang, W.; Huang, Y.-Y.; Efferth, T.; Wang, H.-M.; Fu, Y.-J. Efficient extraction and preparative separation of four main isoflavonoids from Dalbergia odorifera T. Chen leaves by deep eutectic solvents-based negative pressure cavitation extraction followed by macroporous resin column chromatography. J. Chromatogr. B 2016, 1033-1034, 40-48. [CrossRef] [PubMed]

58. Qi, X.-L.; Peng, X.; Huang, Y.-Y.; Li, L.; Wei, Z.-F.; Zu, Y.-G.; Fu, Y.-J. Green and efficient extraction of bioactive flavonoids from Equisetum palustre L. by deep eutectic solvents-based negative pressure cavitation method combined with macroporous resin enrichment. Ind. Crop. Prod. 2015, 70, 142-148. [CrossRef]

59. Machmudah, S.; Lestari, S.D.; Widiyastuti, W.; Diono, W.; Kanda, H.; Winardi, S.; Goto, M. Subcritical water extraction enhancement by adding deep eutectic solvent for extracting xanthone from mangosteen pericarps. J. Supercrit. Fluids 2018, 133, 615-624. [CrossRef]

60. Shen, D.; Kou, X.; Wu, C.; Fan, G.; Li, T.; Dou, J.; Wang, H.; Zhu, J. Cocktail enzyme-assisted alkaline extraction and identification of jujube peel pigments. Food Chem. 2021, 357, 129747. [CrossRef]

61. Baiano, A. Recovery of biomolecules from food wastes-A review. Molecules 2014, 19, 14821-14842. [CrossRef] [PubMed]

62. Nadar, S.; Rao, P.; Rathod, V.K. Enzyme assisted extraction of biomolecules as an approach to novel extraction technology: A review. Food Res. Int. 2018, 108, 309-330. [CrossRef]

63. Liang, J.; Zeng, Y.; Wang, H.; Lou, W. Extraction, purification and antioxidant activity of novel polysaccharides from Dendrobium officinale by deep eutectic solvents. Nat. Prod. Res. 2018, 33, 3248-3253. [CrossRef]

64. Ferreira, I.C.; Martins, N.; Barros, L. Phenolic compounds and its bioavailability: In vitro bioactive compounds or health promoters. In Advances in Food and Nutrition Research; Elsevier: Amsterdam, The Netherlands, 2017; pp. 1-44.

65. Asnin, L.; Park, S.W. Isolation and Analysis of Bioactive Compounds inCapsicumPeppers. Crit. Rev. Food Sci. Nutr. 2014, 55, 254-289. [CrossRef]

66. Ghasemzadeh, A.; Jaafar, H.Z. Profiling of phenolic compounds and their antioxidant and anticancer activities in pandan (Pandanus amaryllifolius Roxb.) extracts from different locations of Malaysia. BMC Complement. Altern. Med. 2013, $13,341$. [CrossRef]

67. Peng, X.; Duan, M.-H.; Yao, X.-H.; Zhang, Y.-H.; Zhao, C.-J.; Zu, Y.-G.; Fu, Y.-J. Green extraction of five target phenolic acids from Lonicerae japonicae Flos with deep eutectic solvent. Sep. Purif. Technol. 2016, 157, 249-257. [CrossRef]

68. Dai, Y.; Witkamp, G.-J.; Verpoorte, R.; Choi, Y.H. Natural Deep Eutectic Solvents as a New Extraction Media for Phenolic Metabolites in Carthamus tinctorius L. Anal. Chem. 2013, 85, 6272-6278. [CrossRef] [PubMed]

69. Bubalo, M.C.; Ćurko, N.; Tomašević, M.; Ganić, K.K.; Redovniković, I.R. Green extraction of grape skin phenolics by using deep eutectic solvents. Food Chem. 2016, 200, 159-166. [CrossRef]

70. Panić, M.; Stojković, M.R.; Kraljić, K.; Škevin, D.; Redovniković, I.R.; Srček, V.G.; Radošević, K. Ready-to-use green polyphenolic extracts from food by-products. Food Chem. 2019, 283, 628-636. [CrossRef]

71. Warner, R.; Wu, B.-S.; MacPherson, S.; Lefsrud, M. A Review of Strawberry Photobiology and Fruit Flavonoids in Controlled Environments. Front. Plant Sci. 2021, 12, 611893. [CrossRef] 
72. Abidin, M.H.Z.; Abdullah, N.; Abidin, N.Z. Protective Effect of Antioxidant Extracts from Grey Oyster Mushroom, Pleurotus pulmonarius (Agaricomycetes), Against Human Low-Density Lipoprotein Oxidation and Aortic Endothelial Cell Damage. Int. J. Med. Mushrooms 2016, 18, 109-121. [CrossRef]

73. Sun, F.; Zheng, X.Y.; Ye, J.; Wu, T.T.; Wang, J.L.; Chen, W. Potential Anticancer Activity of Myricetin in Human T24 Bladder Cancer Cells Both In Vitro and In Vivo. Nutr. Cancer 2012, 64, 599-606. [CrossRef] [PubMed]

74. Madende, M.; Kemp, G.; Stoychev, S.; Osthoff, G. Characterization of African elephant beta-casein and its relevance to the chemistry of caseins and casein micelles. Int. Dairy J. 2018, 85, 112-120. [CrossRef]

75. Xia, G.-H.; Li, X.-H.; Jiang, Y.-H. Deep eutectic solvents as green media for flavonoids extraction from the rhizomes of Polygonatum odoratum. Alex. Eng. J. 2020, 60, 1991-2000. [CrossRef]

76. Zhuang, B.; Dou, L.-L.; Li, P.; Liu, E.-H. Deep eutectic solvents as green media for extraction of flavonoid glycosides and aglycones from Platycladi Cacumen. J. Pharm. Biomed. Anal. 2017, 134, 214-219. [CrossRef] [PubMed]

77. Cao, H.; Song, S.; Zhang, H.; Zhang, Y.; Qu, R.; Yang, B.; Jing, Y.; Hu, T.; Yan, F.; Wang, B. Chemopreventive effects of berberine on intestinal tumor development in Apc min/+mice. BMC Gastroenterol. 2013, 13, 163. [CrossRef]

78. Carrara, V.S.; Filho, L.C.; Garcia, V.A.S.; Faiões, V.S.; Cunha-Junior, E.; Torres-Santos, E.C.; Cortez, D.A.G. Supercritical Fluid Extraction of Pyrrolidine Alkaloid from Leaves of Piper amalago L. Evid.-Based Complement. Altern. Med. 2017, $2017,7401748$. [CrossRef]

79. Li, L.; Huang, M.; Shao, J.; Lin, B.; Shen, Q. Rapid determination of alkaloids in Macleaya cordata using ionic liquid extraction followed by multiple reaction monitoring UPLC-MS/MS analysis. J. Pharm. Biomed. Anal. 2016, 135, 61-66. [CrossRef]

80. Duan, L.; Dou, L.-L.; Guo, L.; Li, P.; Liu, E.-H. Comprehensive Evaluation of Deep Eutectic Solvents in Extraction of Bioactive Natural Products. ACS Sustain. Chem. Eng. 2016, 4, 2405-2411. [CrossRef]

81. Takla, S.S.; Shawky, E.; Hammoda, H.M.; Darwish, F.A. Green techniques in comparison to conventional ones in the extraction of Amaryllidaceae alkaloids: Best solvents selection and parameters optimization. J. Chromatogr. A 2018, 1567, 99-110. [CrossRef]

82. Espino, M.; Solari, M.; Fernández, M.D.L.A.; Boiteux, J.; Gómez, M.R.; Silva, M.F. NADES-mediated folk plant extracts as novel antifungal agents against Candida albicans. J. Pharm. Biomed. Anal. 2019, 167, 15-20. [CrossRef] [PubMed]

83. López, C.J.; Caleja, C.; Prieto, M.A.; Barreiro, M.F.; Barros, L.; Ferreira, I.C.F.R. Optimization and comparison of heat and ultrasound assisted extraction techniques to obtain anthocyanin compounds from Arbutus unedo L. fruits. Food Chem. 2018, 264, 81-91. [CrossRef]

84. Jeong, K.M.; Lee, M.S.; Nam, M.W.; Zhao, J.; Jin, Y.; Lee, D.-K.; Kwon, S.W.; Jeong, J.H.; Lee, J. Tailoring and recycling of deep eutectic solvents as sustainable and efficient extraction media. J. Chromatogr. A 2015, 1424, 10-17. [CrossRef] [PubMed]

85. Chen, L.; Huang, G. The antiviral activity of polysaccharides and their derivatives. Int. J. Biol. Macromol. 2018, 115, 77-82. [CrossRef]

86. Chen, L.; Huang, G. Extraction, characterization and antioxidant activities of pumpkin polysaccharide. Int. J. Biol. Macromol. 2018, 118, 770-774. [CrossRef] [PubMed]

87. Gao, C.; Cai, C.; Liu, J.; Wang, Y.; Chen, Y.; Wang, L.; Tan, Z. Extraction and preliminary purification of polysaccharides from Camellia oleifera Abel. seed cake using a thermoseparating aqueous two-phase system based on EOPO copolymer and deep eutectic solvents. Food Chem. 2020, 313, 126164. [CrossRef] [PubMed]

88. Barbieri, J.B.; Goltz, C.; Cavalheiro, F.B.; Toci, A.T.; Igarashi-Mafra, L.; Mafra, M.R. Deep eutectic solvents applied in the extraction and stabilization of rosemary (Rosmarinus officinalis L.) phenolic compounds. Ind. Crop. Prod. 2019, 144, 112049. [CrossRef]

89. Shafie, M.H.; Yusof, R.; Gan, C.-Y. Deep eutectic solvents (DES) mediated extraction of pectin from Averrhoa bilimbi: Optimization and characterization studies. Carbohydr. Polym. 2019, 216, 303-311. [CrossRef]

90. Rathnasamy, S.K.; Rajendran, D.S.; Balaraman, H.B.; Viswanathan, G. Functional deep eutectic solvent-based chaotic extraction of phycobiliprotein using microwave-assisted liquid-liquid micro-extraction from Spirulina (Arthrospira platensis) and its biological activity determination. Algal Res. 2019, 44, 101709. [CrossRef]

91. Rajha, H.N.; Mhanna, T.; El Kantar, S.; El Khoury, A.; Louka, N.; Maroun, R.G. Innovative process of polyphenol recovery from pomegranate peels by combining green deep eutectic solvents and a new infrared technology. LWT 2019, 111, 138-146. [CrossRef]

92. Hao, C.; Chen, L.; Dong, H.; Xing, W.; Xue, F.; Cheng, Y. Extraction of Flavonoids from Scutellariae Radix using UltrasoundAssisted Deep Eutectic Solvents and Evaluation of Their Anti-Inflammatory Activities. ACS Omega 2020, 5, $23140-23147$. [CrossRef]

93. Shafie, M.H.; Gan, C.-Y. Could choline chloride-citric acid monohydrate molar ratio in deep eutectic solvent affect structural, functional and antioxidant properties of pectin? Int. J. Biol. Macromol. 2020, 149, 835-843. [CrossRef]

94. Jeong, K.M.; Ko, J.; Zhao, J.; Jin, Y.; Yoo, D.E.; Han, S.Y.; Lee, J. Multi-functioning deep eutectic solvents as extraction and storage media for bioactive natural products that are readily applicable to cosmetic products. J. Clean. Prod. 2017, 151, 87-95. [CrossRef]

95. Shang, X.; Dou, Y.; Zhang, Y.; Tan, J.-N.; Liu, X.; Zhang, Z. Tailor-made natural deep eutectic solvents for green extraction of isoflavones from chickpea (Cicer arietinum L.) sprouts. Ind. Crop. Prod. 2019, 140, 111724. [CrossRef]

96. Shang, X.; Tan, J.-N.; Du, Y.; Liu, X.; Zhang, Z. Environmentally-Friendly Extraction of Flavonoids from Cyclocarya paliurus (Batal.) Iljinskaja Leaves with Deep Eutectic Solvents and Evaluation of Their Antioxidant Activities. Molecules 2018, $23,2110$. [CrossRef] [PubMed]

97. Liu, Y.; Li, J.; Fu, R.; Zhang, L.; Wang, D.; Wang, S. Enhanced extraction of natural pigments from Curcuma longa L. using natural deep eutectic solvents. Ind. Crop. Prod. 2019, 140, 111620. [CrossRef] 
98. Gullón, B.; Muñiz-Mouro, A.; Lú-Chau, T.A.; Moreira, M.T.; Lema, J.; Eibes, G. Green approaches for the extraction of antioxidants from eucalyptus leaves. Ind. Crop. Prod. 2019, 138, 111473. [CrossRef]

99. Cao, J.; Chen, L.; Li, M.; Cao, F.; Zhao, L.; Su, E. Efficient extraction of proanthocyanidin from Ginkgo biloba leaves employing rationally designed deep eutectic solvent-water mixture and evaluation of the antioxidant activity. J. Pharm. Biomed. Anal. 2018, 158, 317-326. [CrossRef]

100. Radošević, K.; Ćurko, N.; Srček, V.G.; Bubalo, M.C.; Tomašević, M.; Ganić, K.K.; Redovniković, I.R. Natural deep eutectic solvents as beneficial extractants for enhancement of plant extracts bioactivity. LWT 2016, 73, 45-51. [CrossRef]

101. Jeong, K.M.; Zhao, J.; Jin, Y.; Heo, S.R.; Han, S.Y.; Yoo, D.E.; Lee, J. Highly efficient extraction of anthocyanins from grape skin using deep eutectic solvents as green and tunable media. Arch. Pharmacal Res. 2015, 38, 2143-2152. [CrossRef]

102. Benlebna, M.; Ruesgas-Ramón, M.; Bonafos, B.; Fouret, G.; Casas, F.; Coudray, C.; Durand, E.; Figueroa-Espinoza, M.C.; Feillet-Coudray, C. Toxicity of Natural Deep Eutectic Solvent Betaine:Glycerol in Rats. J. Agric. Food Chem. 2018, 66, 6205-6212. [CrossRef] [PubMed]

103. Oktaviyanti, N.D.; Kartini; Mun'Im, A. Application and optimization of ultrasound-assisted deep eutectic solvent for the extraction of new skin-lightening cosmetic materials from Ixora javanica flower. Heliyon 2019, 5, e02950. [CrossRef]

104. Mouratoglou, E.; Malliou, V.; Makris, D.P. Novel Glycerol-Based Natural Eutectic Mixtures and Their Efficiency in the UltrasoundAssisted Extraction of Antioxidant Polyphenols from Agri-Food Waste Biomass. Waste Biomass Valorization 2016, 7, $1377-1387$. [CrossRef]

105. Jeong, K.M.; Jin, Y.; Yoo, D.E.; Han, S.Y.; Kim, E.M.; Lee, J. One-step sample preparation for convenient examination of volatile monoterpenes and phenolic compounds in peppermint leaves using deep eutectic solvents. Food Chem. 2018, 251, 69-76. [CrossRef] [PubMed]

106. Athanasiadis, V.; Grigorakis, S.; Lalas, S.; Makris, D.P. Highly Efficient Extraction of Antioxidant Polyphenols from Olea europaea Leaves Using an Eco-friendly Glycerol/Glycine Deep Eutectic Solvent. Waste Biomass Valorization 2017, 9, 1985-1992. [CrossRef]

107. Pal, C.B.T.; Jadeja, G.C. Deep eutectic solvent-based extraction of polyphenolic antioxidants from onion (Allium cepa L.) peel. J. Sci. Food Agric. 2018, 99, 1969-1979. [CrossRef]

108. Škulcova, A.; Haščičová, Z.; Hrdlička, L.; Sima, J.; Jablonský, M. Green solvents based on choline chloride for the extraction of spruce bark (Picea abies). Cellul. Chem. Technol. 2017, 52, 3-4.

109. Koutsoukos, S.; Tsiaka, T.; Tzani, A.; Zoumpoulakis, P.; Detsi, A. Choline chloride and tartaric acid, a Natural Deep Eutectic Solvent for the efficient extraction of phenolic and carotenoid compounds. J. Clean. Prod. 2019, 241, 118384. [CrossRef]

110. Kumar, A.K.; Parikh, B.S.; Pravakar, M. Natural deep eutectic solvent mediated pretreatment of rice straw: Bioanalytical characterization of lignin extract and enzymatic hydrolysis of pretreated biomass residue. Environ. Sci. Pollut. Res. 2015, 23, 9265-9275. [CrossRef]

111. Kumar, A.K.; Parikh, B.S.; Shah, E.; Liu, L.Z.; Cotta, M.A. Cellulosic ethanol production from green solvent-pretreated rice straw. Biocatal. Agric. Biotechnol. 2016, 7, 14-23. [CrossRef]

112. Jancheva, M.; Grigorakis, S.; Loupassaki, S.; Makris, D.P. Optimised extraction of antioxidant polyphenols from Satureja thymbra using newly designed glycerol-based natural low-transition temperature mixtures (LTTMs). J. Appl. Res. Med. Aromat. Plants 2017, 6, 31-40. [CrossRef]

113. Asghar, A.; Butt, M.S.; Shahid, M.; Huang, Q. Evaluating the antimicrobial potential of green cardamom essential oil focusing on quorum sensing inhibition of Chromobacterium violaceum. J. Food Sci. Technol. 2017, 54, 2306-2315. [CrossRef]

114. Liu, W.; Zhang, K.; Chen, J.; Yu, J. Ascorbic acid and choline chloride: A new natural deep eutectic solvent for extracting tert-butylhydroquinone antioxidant. J. Mol. Liq. 2018, 260, 173-179. [CrossRef]

115. Yoo, D.E.; Jeong, K.M.; Han, S.Y.; Kim, E.M.; Jin, Y.; Lee, J. Deep eutectic solvent-based valorization of spent coffee grounds. Food Chem. 2018, 255, 357-364. [CrossRef]

116. Shamseddin, A.; Crauste, C.; Durand, E.; Villeneuve, P.; Dubois, G.; Durand, T.; Vercauteren, J.; Veas, F. Resveratrol formulated with a natural deep eutectic solvent inhibits active matrix metalloprotease-9 in hormetic conditions. Eur. J. Lipid Sci. Technol. 2017, 119, 1700171. [CrossRef]

117. Juneidi, I.; Hayyan, M.; Hashim, M.A. Evaluation of toxicity and biodegradability for cholinium-based deep eutectic solvents. RSC Adv. 2015, 5, 83636-83647. [CrossRef]

118. Wen, Q.; Chen, J.-X.; Tang, Y.-L.; Wang, J.; Yang, Z. Assessing the toxicity and biodegradability of deep eutectic solvents. Chemosphere 2015, 132, 63-69. [CrossRef] [PubMed]

119. Francisco, M.; Bruinhorst, A.V.D.; Kroon, M.C. Low-Transition-Temperature Mixtures (LTTMs): A New Generation of Designer Solvents. Angew. Chem. Int. Ed. 2013, 52, 3074-3085. [CrossRef] [PubMed]

120. González, C.G.; Mustafa, N.R.; Wilson, E.G.; Verpoorte, R.; Choi, Y.H. Application of natural deep eutectic solvents for the "green"extraction of vanillin from vanilla pods. Flavour Fragr. J. 2017, 33, 91-96. [CrossRef]

121. Radošević, K.; Bubalo, M.C.; Srček, V.G.; Grgas, D.; Dragičević, T.L.; Redovniković, I.R. Evaluation of toxicity and biodegradability of choline chloride based deep eutectic solvents. Ecotoxicol. Environ. Saf. 2015, 112, 46-53. [CrossRef] [PubMed]

122. Socas-Rodríguez, B.; Torres-Cornejo, M.; Álvarez-Rivera, G.; Mendiola, J. Deep Eutectic Solvents for the Extraction of Bioactive Compounds from Natural Sources and Agricultural By-Products. Appl. Sci. 2021, 11, 4897. [CrossRef]

123. Hayyan, M.; Hashim, M.A.; Hayyan, A.; Al-Saadi, M.A.; Al-Nashef, I.M.; Mirghani, M.E.S.; Saheed, O.K. Are deep eutectic solvents benign or toxic? Chemosphere 2013, 90, 2193-2195. [CrossRef] 